
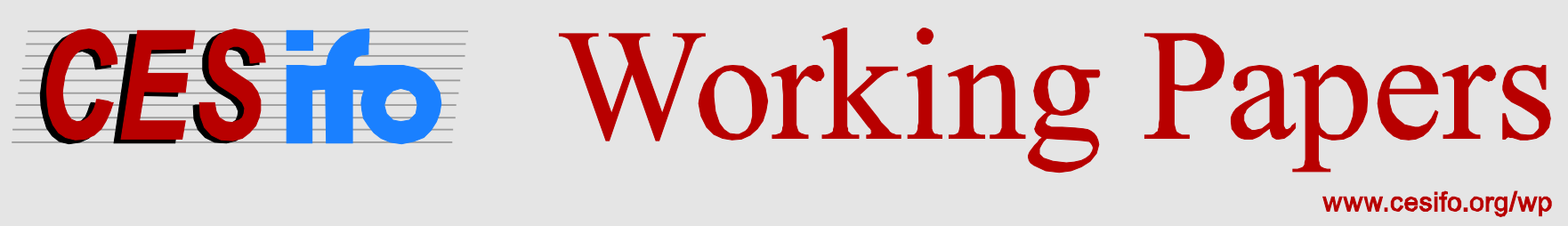

\title{
I Spy with my Little Eye... a Banking Crisis Early Warnings and Incentive Schemes in Banks
}

\author{
Hendrik Hakenes \\ Friederike Schlegel
}

CESIFO WORKING PAPER NO. 5140

CATEGORY 11: INDUSTRIAL ORGANISATION

DECEMBER 2014

An electronic version of the paper may be downloaded

- from the SSRN website:

- from the RePEc website:

- from the CESifo website:

WWW.SSRN.com

www.RePEc.org

www.CESifo-group.org/wp

\section{CESifo}




\title{
I Spy with my Little Eye... a Banking Crisis Early Warnings and Incentive Schemes in Banks
}

\begin{abstract}
The severity and depth of the recent financial crisis hit many by surprise. Despite warning signs, the financial system seems to have been unable to aggregate existing information. As the events of Fall 2008 showed, many investors were caught off guard by the large number of banks collapsing worldwide. But what triggers an early warning, and what are the incentives to implement such a trigger? We construct a theoretical model of a bank that is financed with debt and equity, and a bank manager monitoring the bank's loan portfolio. The manager must be incentivized to warn the board before a crisis. However, we show that the board may implement a contract with insufficient incentives to communicate a warning, as refinancing conditions deteriorate when lenders notice an upcoming crisis. We discuss policies to improve information efficiency and give conditions under which regulatory measures, such as capital and liquidity regulation, increase welfare.
\end{abstract}

JEL-Code: G010, G210, L220.

Keywords: banking crises, information propagation, information efficiency, incentives, compensation regulation.

\author{
Hendrik Hakenes* \\ University of Bonn \\ Adenauerallee 24-42 \\ Germany - 53113 Bonn \\ hakenes@uni-bonn.de
}

\author{
Friederike Schlegel \\ University of Bonn \\ Adenauerallee 24-42 \\ Germany - 53113 Bonn \\ schlegel@uni-bonn.de
}

*corresponding author

December 5, 2014

We thank Christina Bannier, Patrick Bolton, Christian Eufinger, Thomas Gall, Robert Hauswald, Roland Kirstein, Matthias Kräkel, Christian Kuklick, John H. Moore, Mark Le Quement, Ailsa Röell, Robert Ryan, Javier Suarez, and audiences in Rome, LMU Munich, Mannheim, Göttingen, Augsburg, Düsseldorf, Münster and Hannover for discussion. All errors are our own. 
"Powerful few saw crash coming: I think a lot of people actually saw this train barreling down the tracks, CEOs, people in government, and they weren't telling us."

Andrew Ross Sorkin, New York Times columnist, 2009

\section{Introduction}

The financial crisis came as a surprise to financial markets and institutions. This is startling, given that warnings had been issued in a number of notes and articles (see, e. g., Shiller, 2005; Rajan, 2006). ${ }^{1}$ As early as 2004, the chief economist of the Northern Trust Corporation, Paul Kasriel, had warned of increased risk in the housing markets and the enormous effect this could have on the banking system and the whole economy; on the organizational level, inside individual banks, many expected a credit crunch (Kasriel, 2004). However, information often was only available within the institutions, but not revealed to outsiders. When the information was publicly available, it seemed to have gone largely unnoticed. How could the necessary information not have reached the relevant regulatory authorities? How did banks predominantly go into the crisis unprepared? How was it possible that a crisis of this magnitude had not been anticipated?

The propagation of information in banking plays a role in other, more specific, contexts such as banking regulation. Responding to the recent financial crisis, the U.S. Congress passed the Dodd-Frank Act, establishing the Financial Stability Oversight Council (FSOC). Its task is to identify and monitor excessive risks to the financial system. This central institution, which collects all available information regarding financial stability and provides early warnings, is meant to help prevent future crises. However, the crucial question is how to make information available to the FSOC in the first place, and how to set incentives for insiders to communicate significant information. This question is especially interesting in the current discussion regarding banking regulation and policy measures meant to avert a similar crisis in the future; such policies should emphasize the importance of making early warnings available.

We construct a theoretical model with endogenous communication of warning signals in a bank. There are three agents: the board representing the bank's owners, a bank manager, and lenders. The bank is financed with short-term debt and equity. It invests in a project, e. g., a loan portfolio. The project can be in one of three states (good, critical, and default). In the good state, it cannot fail immediately. It must first pass through the critical state before potentially defaulting. By

\footnotetext{
${ }^{1}$ For instance, Rajan (2006) pointed out: "The inter-bank market could freeze up, and one could well have a full blown financial crisis."
} 
modeling a single bank, we abstract from issues of systemic risk from individual institutional risk.

The manager is needed to monitor the project. Monitoring is costly, but reduces the probability of default and informs the manager about the state of the project. The manager can decide to use this information about the state of the project to report the transition from good to critical to the board. The board can then react to cut losses. Hence, the manager's report is needed as an early warning.

The report has endogenous negative consequences for the manager; hence, she needs to be incentivized to warn the board. But if the board reacts, this action is observed by financial markets (lenders), and the bank's refinancing conditions deteriorate. In reality, it is often the case that not only bank owners might receive available information but also financial markets. In addition, policy changes in banks are well observed by market participants and analysts. Because of this externality that interacts with financial markets, the board itself faces a reduced incentive to set up a compensation package that achieves informational efficiency. We seek to identify the conditions under which contractual arrangements will enable the propagation of critical information. In other words, we will examine which factors influence the financial market's informational efficiency.

From our analysis, we obtain a number of predictions. First, the functioning of the information channel depends on the bank's equity ratio. The higher the bank's leverage, the more it is affected by a deterioration of its refinancing conditions resulting from the revelation of negative information; thus, the board is less prone to implement the efficient contract. Second, the functioning of information transmission depends on the project's returns. If the profitability of the project is low (for example, due to high competition in the banking sector), then the board will gain nothing from incentivizing the manager to monitor the project. Before and during a financial crisis, both of these conditions typically arise; the bank leverage is likely to increase and bank asset value drops. These effects tend to restrict the information channel.

The model lends itself to discussing policy measures. It can be used to analyze what types of financial regulation prevents the restriction of the information channel. First, capital regulation has a positive effect on the propagation of critical information. The higher the capital restrictions, the more likely the manager will communicate the critical state. On the other hand, capital restrictions limit overall investment size. In our setup, both effects imply that stricter capital standards increase welfare under certain conditions; for example, welfare may increase if profitability of the project or the probability of the negative signal is not too high. Further, we argue that risk-sensitive capital regulation does not improve the system's informativeness. Under such regulation, the bank would fear an even more severe reaction to negative signals. Second, the presence of more 
liquid assets increases the bank's desire to receive early warning signals. Consequently, regulating the bank's asset's liquidity may induce the bank to implement the informative contract. Third, we also find that the information channel can be kept open if contingent convertible bonds are used for refinancing rather than straight bonds. These bonds are converted into shares after a drop in the bank's share price; this situation would arise after the negative information is communicated by the manager. In our setting, the conversion must come at a loss for lenders. This loss is anticipated; hence, interest rates before the conversion increase. However, the information is less detrimental to the bank; after the conversion, it no longer needs to fear an increase in refinancing rates. The negative side effect from an informative contract is reduced.

The remainder of the paper is organized as follows. After a discussion of the related literature, section 2 presents the theoretical model. Section 3 discusses equilibria: the communication equilibrium (in 3.1), the no-communication equilibrium with monitoring (in 3.2), a mixed-strategy equilibrium (in 3.3) and the no-monitoring equilibrium (in 3.4). Subsection 3.5 discusses conditions required to reach the different equilibria. Section 4 discusses the many policy implications mentioned above, starting with a welfare analysis. Section 5 concludes. Proofs are in the appendix.

Literature. Our paper relates to many strands of the economic literature. First, the paper is connected to agency theory within corporate finance. It is related to Levitt and Snyder (1997), in which the authors analyze incentives for agents to reveal early warnings to the principal. The authors find that it is necessary for the principal to compensate the agent for being honest even if this means admitting that prospects are not good; our paper reaches a similar conclusion. Their model concentrates on incentive contracts between agents and the principal; in contrast, our model includes the financing structure and investors. Early warnings are also examined by Povel (1999) under the consideration of bankruptcy. Eisfeldt and Rampini (2008) empirically analyze incentives for managers to reveal private information about optimal capital allocation. Aghion and Tirole (1997) discuss the benefits of delegating formal authority versus the costs of losing it in respect of the transfer or information. Benmelech, Kandel, and Veronesi (2010) find that stock-based compensation induces managers to exert costly effort and to hide bad news about future growth options. This may result in suboptimal investment. Another paper that discusses lack of information in a principal-agent setting is by Kanodia, Bushman, and Dickhaut (1989). In their model, agents do not change decisions once they are made. This arises because agents fear revealing negative information about their human capital by admitting that they did not initially choose the best strategy. Furthermore, there are a number of related empirical articles in the field of banking and compensation systems in banking 
(see Fahlenbrach and Stulz, 2011; Barro and Barro, 1990; John, Mehran, and Qian, 2010). The choice of compensation contracts in our model exerts a large influence on the information channel before and during a financial crisis.

The literature on financial reporting is vast (see Verrecchia, 2001, for a survey). In this literature, financial reporting is viewed as a tool to mitigate and resolve agency problems. An example is Laux, Lóránth, and Morrison (2009), which is closely related to our model. The authors analyze the interdependence between internal information transmission and loan officer compensation in banks. However, for our model, the externality of information on loan rates is crucial; their focus is inside the bank. Furthermore, there is a literature on dynamic contracting under asymmetric information. For example, Quadrini (2004) and DeMarzo and Fishman (2007) attempt to find and analyze contracts that reveal full information. Our result verifies that the transfer of information is welfare-optimal if effort costs are not too high. We also discuss policy implications for reaching the equilibrium characterized by communication and full information. However, the full revelation principle does not apply in our setting because we restrict our setting to short-term contracts.

The heart of our paper is a moral hazard model in continuous time. The continuoustime moral hazard literature is very lively, see Biais, Mariotti, Plantin, and Rochet (2007); Biais, Mariotti, Rochet, and Villeneuve (2010); Pagès and Possamai (2012); Pagès (2013) and DeMarzo and Sannikov (2006); Sannikov (2007, 2008). In these papers, the agent typically controls the drift of a Brownian motion process. However, we keep the model as simple as possible, basing it on a three-state Markov process. This is meant to capture the deterioration of a loan's rating class, which can be influenced by the loan officer.

The communication of bad news is somewhat similar to the communication of fraud, which is the basis of the literature on whistleblowing. Dyck, Morse, and Zingales (2010) analyze data about corporate fraud that took place in the U.S. and the actors that detected the fraud. They find that employees seem to lose outright from whistleblowing. This result underlines the need for better incentives for communication. In a dynamic setting, Povel, Singh, and Winton (2007) examine the incentives of managers to commit fraud when firms seek funding from investors and investors can obtain a better signal about the true perspectives of the firm through costly monitoring. In contrast to our model, fraud is not modeled to lead to a crisis or recession; however, the incentives for fraud do change over the business cycle.

There are a number of articles that assume strategic ignorance; that is, these papers develop models in which failure to collect information may have a positive effect on an agent (Carrillo and Mariotti, 2000; Kessler, 1998). In our model, the bank owners choose to remain ignorant for a reason. The critical information is 
valuable to them only if they act upon it. But the action cannot be hidden, and the revelation of information creates a negative externality: financing costs increase. Therefore, bank owners may choose not to pay the manager to reveal the information; instead, they may decide to remain ignorant.

\section{The Model}

Consider a continuous-time economy with three types of agents: a bank's board of directors (the board), a bank manager (the manager) and lenders. The structure of the model is depicted in Figure 1. The board takes decisions on behalf of the owners (equity investors), who provide an endowment of $E$. The board and equity investors are risk-neutral and do not discount the future.

The bank can invest in a project (a loan portfolio) of size $I>E$ that pays a continuous return of $R$ per unit of investment each period until it defaults. Thus, the project potentially has an infinite maturity. In reality, banks engage in maturity transformation in which they hold assets of long maturity while refinancing with short maturities. Our choices of infinite maturity and continuous time are not crucial, but they keep the model tractable. As also non-banks undertake maturity transformation, our model can also be applied in the context of other companies. However, we model the firm as a bank because the mismatch of maturities is typical for banking business and is therefore a perfect example.

The project can be in three different states: class A (good), class B (critical), and default. In state $B$, projects can default at any time, and the default intensity is $\beta$. In state $\mathrm{A}$, projects cannot default immediately; they first deteriorate to class $B$ and emit a negative signal only observed by the manager. The instantaneous probability of such a downgrade is $\alpha<\beta$ if the project is monitored by the manager, and $\alpha+\gamma$ if not monitored. Formally, we have a Markov chain with three states: A, B, and the default state. Transitions move only in one direction: from A to $B$ and from $B$ to default. ${ }^{2}$ Default is an absorbing state. The transition probability from A to $\mathrm{B}$ can be controlled by the manager. The board and the lenders cannot observe whether the project is in state A or B. Of course, when the cash flow stops, they conclude that the project is in default. They also know the parameters $\alpha, \beta$, and $\gamma$. Initially, the project is in state $\mathrm{A}$ with probability $(\beta-\alpha) / \beta$,

\footnotetext{
${ }^{2}$ One can also think of transitions in reverse directions. However, we assume here an aggregated transition rate from A over B to default, as we are interested in the events happening in the case of a deteriorating situation.
} 
or in state B with probability $\alpha / \beta{ }^{3}$

Monitoring is carried out by the manager; the instantaneous monitoring cost is $c$ per unit of investment. The monitoring choice is not observable. The manager is risk-neutral and has a discount rate of $\rho{ }^{4}$ Discounting implies that the manager prefers her salary to be paid out early. Deferring payments comes at a cost. The manager's opportunity wage is $w_{0}$, which is normalized to $w_{0}=0$ without loss of generality.

The manager's contract can depend only on observable parameters. There can be a wage level $w$ before the manager communicates the downgrade and a onetime payment $H$ when the manager communicates the downgrade. Because of the structure of the model, $w$ is constant over time. Hence, the contract consists of two variables: a wage $w$ and a reward $H$. The setting contains two problems of asymmetric information: hidden action (the manager is able to shirk instead of monitoring the project) and hidden information (the manager may conceal the negative signal). The incentive wage $w$ can be conceptualized as a bonus payment, whereas $H$ can be paid as part of an employee suggestion system or on the basis of target agreements. If the project is in class B, the bank can save wages by terminating incentive wages. For a class $\mathrm{B}$ project, monitoring has no positive effect. Therefore, the information about a class transition is valuable because it enables the bank manager to concentrate on other projects and allows the bank to save wage costs. In reality, the benefit of an early warning will be much larger: the loan portfolio can be restructured, or risk provisions can be accumulated. Models containing such richer structure yields qualitatively similar results, hence we stick to the simplest modeling choice without further benefits.

Lenders are risk-neutral and do not discount. They have an endowment $\geq I-E$; thus, they can provide financing for the project. There is debt finance, where $D=I-E$ is the amount of debt. The lenders lend at a competitive rate, hence the risk-free rate is zero. For the actual interest rate $r$, lenders take into account the current default risk. The lenders observe when the manager is assigned new tasks or at least is removed from her initial duties. They do not observe the actual wage contract for the manager. All contracts (debt and labor contracts) are shortterm; there is no long-term commitment. Consequently, the contracting space is

\footnotetext{
${ }^{3}$ This assumption is not critical, but simplifies the analysis. With this initial setting, the expected project quality is unchanged as long as the manager monitors; the fraction of projects moving from $A$ to $B$ is as large as the fraction moving from $B$ to default. Hence, the proportion of A-projects to B-projects is constant, and so is the probability of default. Mathematically, we start on an eigenvalue of the dynamic system.

${ }^{4}$ The assumption that managers discount more heavily is standard in the corporate finance literature, see for example Tirole (2006), based on Aghion, Bolton, and Tirole (2004). This assumption is used to endogenize short-term compensation.
} 
Figure 1: Structure of the Model

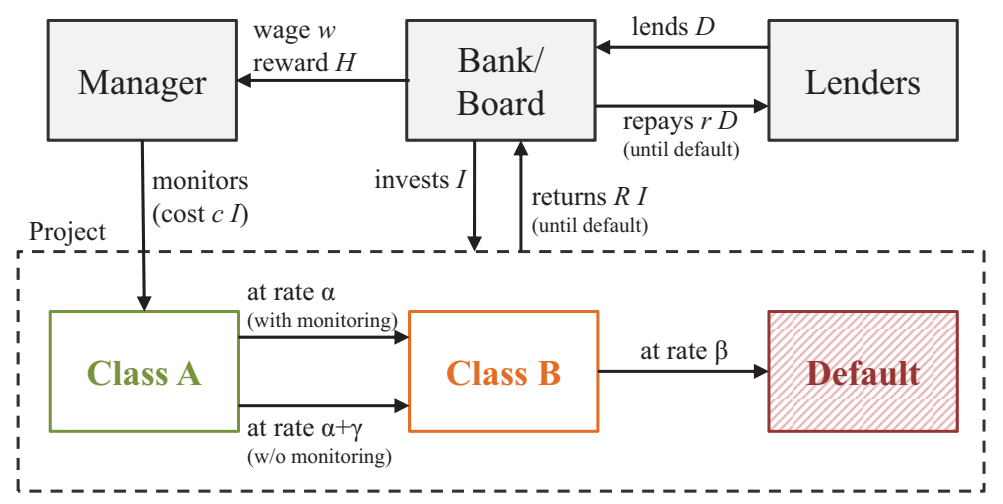

incomplete. Short-term contracting is consistent with the maturity transformation that banks carry out given a long-term project.

One can interpret this model as follows. The manager is a bank employee who is incentivized to monitor a loan portfolio. She can observe the quality of the loan (A or B). Loans in class B can default at any time, so the manager can exert monitoring effort to reach the lower transition rate $\alpha$ instead of $\alpha+\gamma$ and keep the loans in class A as long as possible. Because the effort choice is not observable, the manager collects an additional rent as incentive, which she does not want to lose. The board would like to know the class of the loans. It wants to act upon that information; for example, the board might restructure a loan that deteriorates, or it might increase reserves. In our model, the advantage of early information is endogenous. The manager discounts at a higher rate, so she wants her salary as early as possible. As long as the manager needs to be incentivized, wages must be paid continuously so that monitoring does not break down. When the project is in class B, the manager's effort is no longer needed. Thus, the board benefits from paying only the opportunity costs of the manager, $w_{0}=0$, after the transition date. There is no need to promise future incentive wages.

In sum, a compensation package is offered to incentivize the manager. However, when negative information arrives, this package is modified, to the detriment of the manager. Therefore, the manager reports the loan's deterioration only reluctantly. She needs to be compensated to do so; for example, she may be offered a one-off reward $H$ for communicating.

The revelation of private information by the manager is desirable for the bank because the bank is able to save money by saving wage costs. In recent years, many banks reduced bonuses and salaries in response to the financial crisis. ${ }^{5}$ In reality,

\footnotetext{
${ }^{5}$ See the Huffington Post, 26.01.2012: "BofA, Credit Suisse the Latest Banks to Reduce Banker
} 
many other benefits from the uncovering of a deteriorated situation exist. One of those additional benefits could be a reduction of exposure of the project that is discussed in section 4.3 about liquidity regulation. Further reactions are conceivable. From a welfare perspective, the revelation of signals is also preferable in our model. Managers are compensated with a communication reward for the reduction in wage payments. In total, the economy may be able to save money by an early reaction to negative signals.

The model thus contains the following features. An insider in a leveraged bank has preferential access to information about the bank's assets. She needs to be incentivized to communicate this information. She may see the crisis coming, but not let others know. Giving her the right incentives is costly. The costs are born entirely by the bank, but the bank's lenders also benefit because they can raise interest rates. As a consequence, the board might have insufficient incentives to implement a contract that informs board and markets. Using this model, we can analyze what factors drive information propagation. It is possible that the manager foresees an upcoming crisis, but decision makers and markets are left ignorant.

\section{Equilibrium}

There are three potential types of equilibrium, each characterized by different wage contracts. First, the board can pay the manager zero incentive wages. As a consequence, the manager will not monitor the project, the decay rate of class $\mathrm{A}$ projects is $\alpha+\gamma$ rather than just $\alpha$. This equilibrium is indexed with ' 0 ', denoting no monitoring and no communication. Second, the board can pay the manager an incentive wage until the project defaults, $w>0$, but no reward $H$ for communicating the downturn, $H=0$. In this case, the manager has no incentive to inform the board about the true class of the project, because the board would stop paying incentive wages as soon as it discovered that the project had downgraded to class B. Therefore, the wage cannot depend on the class of the project. In this equilibrium, the wage is just high enough to induce the manager to exert effort (efficiency wage). This equilibrium is indexed with ' $\mathrm{NC}^{\prime}$ for no communication. Third, the board can promise the manager $w>0$ and a one-off reward $H>0$ for revealing when the project moves to class B. Once this information is revealed, the board reacts by reducing the competence and wage of the manager. In this equilibrium, information flows to the board and, as a consequence, to the capital market. Lenders take the board's reaction as negative information and increase

Bonuses." 
interest rates. The advantage of such a reward $H$ is to get the negative information as soon as possible and to be able to react at that time. Otherwise, the incentive payments to the manager would only add to the wage bill. This equilibrium is indexed with a ' $\mathrm{C}$ ' for communication. In an additional equilibrium, the board mixes between ' $\mathrm{C}$ ' and ' $\mathrm{NC}$ ', and there is a parameter range with no investment at all (and thus no bank). We start by discussing the most interesting case: equilibrium $\mathrm{C}$.

\subsection{The Communication Equilibrium (C)}

In this equilibrium, the board pays a positive efficiency wage $w>0$ to the manager until the date when the manager admits that the project class has deteriorated. At that date (called $t_{A}$ ), the manager is promised a one-off reward $H>0$ as a compensation. We now calculate the equilibrium values for $w$ and $H$ and expected profits in equilibrium.

The Lenders. In this equilibrium, the lenders are always informed about the project class. As long as there is no news about the project, it is in class A. When the manager receives the reward and is assigned new tasks, this can only have happened because the class has switched to B. Interest rates $r_{A}$ and $r_{B}$ are set accordingly.

As long as the project is in class A, the lenders know that the instantaneous default rate is zero. Because the opportunity cost of lending is zero they demand a zero interest rate, $r_{A}=0$. After a negative signal, the instantaneous probability of default is $\beta$, so the lenders must be compensated with an interest rate of $r_{B}>0$. The repayment after $\mathrm{d} t$ periods is then $e^{r_{B} \mathrm{~d} t} D$, leading to an expected repayment of $e^{r_{B} \mathrm{~d} t} e^{-\beta \mathrm{d} t} D=e^{\left(r_{B}-\beta\right) \mathrm{d} t} D$. The participation constraint is binding for lenders. The interest rate $r_{B}$ is just sufficient to compensate the lenders for their zero opportunity cost. Hence, $r_{B}=\beta$.

The Manager. In the communication equilibrium $C$, the manager works on the project until she receives and transmits information about a deterioration of the loan's class. At that point, she receives a reward $H$, but her future wage is reduced. Wage $w$ and reward $H$ must be chosen such that the manager behaves as required. Assume for a moment that the manager is making a decision at date $t_{A}$, which is the moment just after the transition from class A to B has occurred. The manager now decides whether to communicate the bad news. If she does, she 
gets a one-off reward $H$. If she does not, she gets the incentive wage $w$ until the project defaults. Her expected utility is then

$$
\begin{aligned}
U_{B} & =\int_{0}^{\infty}\left(\int_{0}^{t_{B}} w e^{-\rho t} \mathrm{~d} t\right) \beta e^{-\beta t_{B}} d t_{B} \\
& =\frac{w}{\beta+\rho} .
\end{aligned}
$$

This utility consists of several parts. The project is already in class $\mathrm{B}$, hence the date $t_{B}$ at which the loan finally defaults is distributed with density $f\left(t_{B}\right)=$ $\beta e^{-\beta t_{B}}$. Until this date, the manager collects her wage $w$, discounted by the factor $e^{-\rho t}$. The reward $H$ must be at least as large as this term. In equilibrium, the inequality is binding, so $H=w /(\beta+\rho)$. Note that the optimal reward $H$ is proportional to the wage $w$. The reward compensates the manager for forgone wages. Hence, the higher the wages, the higher $H$ must be in equilibrium.

The wage $w$ must be high enough to motivate the manager to monitor the project. If she does monitor a loan in class A, the manager's expected utility is

$$
\begin{aligned}
U_{A} & =\int_{0}^{\infty}\left(e^{-\rho t_{A}} H+\int_{0}^{t_{A}}(w-c I) e^{-\rho t} \mathrm{~d} t\right) \alpha e^{-\alpha t_{A}} \mathrm{~d} t_{A} \\
& =\frac{\alpha H+w-c I}{\alpha+\rho} .
\end{aligned}
$$

Again, there are several parts to this expression. If the project is monitored, the stochastic time of transition to class B is distributed with density $f\left(t_{A}\right)=\alpha e^{-\alpha t_{A}}$. At date $t_{A}$, the manager collects the reward $H$, discounted by the factor $e^{-\rho t_{A}}$. Until that date (from now to $t_{A}$ ), she receives the wage $w$, but she exerts effort at $\operatorname{cost} c I$; both of these quantities are discounted by the factor $e^{-\rho t}$.

Now assume the manager decides whether to monitor in the next period of duration $\mathrm{d} t$. If she does monitor, her expected utility is

$$
\alpha \mathrm{d} t H e^{-\rho \mathrm{d} t}+(1-\alpha \mathrm{d} t) U_{A} e^{-\rho \mathrm{d} t}+\left(w e^{-\rho \mathrm{d} t}-c I\right) \mathrm{d} t .
$$

With probability $\alpha \mathrm{d} t$, the class switches from A to B, and the manager collects her reward $H$, which is discounted by $e^{-\rho \mathrm{d} t}$. With probability $(1-\alpha \mathrm{d} t)$, the project remains in class $\mathrm{A}$, and the aggregate future utility is given by $U_{A}$ as expressed in (2). Over the period $\mathrm{d} t$, the wage $w$ is collected and effort costs $c I$ are paid. However, if the manager chooses not to monitor, her expected utility becomes

$$
(\alpha+\gamma) \mathrm{d} t H e^{-\rho \mathrm{d} t}+(1-(\alpha+\gamma) \mathrm{d} t) U_{A} e^{-\rho \mathrm{d} t}+w \mathrm{~d} t
$$

with $U_{A}$ defined in (2). The transition probability increases from $\alpha \mathrm{d} t$ to $(\alpha+\gamma) \mathrm{d} t$, but the manager avoids incurring the effort cost $c I$. In equilibrium, the board sets the wage $w$ just high enough to induce effort, such that $(3)=(4)$. Solving for $w^{*}$ and $H^{*}$ and taking the limit $\mathrm{d} t \rightarrow 0$, we get the following lemma. 
Lemma 1 The optimal wage and reward in the communication equilibrium are

$$
\begin{aligned}
w^{*} & =\frac{(\beta+\rho)(\alpha+\gamma+\rho)}{\gamma \beta} c I \text { and } \\
H^{*} & =\frac{\alpha+\gamma+\rho}{\gamma \beta} c I .
\end{aligned}
$$

The Board. Finally, we calculate the bank's expected profit in this equilibrium. The board implements a contract that pays a wage $w>0$ to the manager. It also pays the manager a reward $H>0$ when a downgrade in the project class is reported. However, the project continues to pay off after the report. The default rate is $\beta$, and while the project does not default, it pays a continuous $R I$. The expected aggregate payoff to the bank, net of interest payments, is

$$
\begin{aligned}
\Pi_{C}= & \frac{\beta-\alpha}{\beta} \int_{0}^{\infty}\left[\int_{0}^{t_{A}}\left(R I-r_{A} D-w^{*}\right) \mathrm{d} t-H\right. \\
& \left.+\int_{t_{A}}^{\infty}\left(\int_{t_{A}}^{t_{B}}\left(R I-r_{B} D\right) \mathrm{d} t\right) \beta e^{-\beta\left(t_{B}-t_{A}\right)} d t_{B}\right] \alpha e^{-\alpha t_{A}} \mathrm{~d} t_{A} \\
+ & \frac{\alpha}{\beta}\left[-H+\int_{0}^{\infty}\left(\int_{0}^{t_{B}}\left(R I-r_{B} D\right) \mathrm{d} t\right) \beta e^{-\beta t_{B}} d t_{B}\right] \\
= & \frac{R I}{\alpha}-H^{*}-\frac{\alpha r_{B} D+(\beta-\alpha)\left(w^{*}+r_{A} D\right)}{\alpha \beta} \\
= & \frac{R I}{\alpha}-D-\frac{(\alpha+\gamma+\rho)\left(\beta^{2}+\rho(\beta-\alpha)\right)}{\gamma \alpha \beta^{2}} c I .
\end{aligned}
$$

There are several parts. The board does not know whether the project is in class A or $\mathbf{B}$ at the start. With probability $(\beta-\alpha) / \beta$, it starts in class $\mathbf{A}$. The date of transition to class $\mathrm{B}, t_{A}$, is stochastic, with density $f\left(t_{A}\right)=\alpha e^{-\alpha t_{A}}$. Until $t_{A}$, the bank receives $R I$ from the project, but pays $r_{A} D$ to lenders and the wage $w$ to the manager. At date $t_{A}$, the manager reports the transition and the board pays the reward $H$. The information becomes public, raising the refinancing rate from $r_{A}=0$ to $r_{B}=\beta$. The project may now default at any time; at date $t_{A}$, the default date $t_{B}$ is distributed with density $f\left(t_{B}\right)=\beta e^{-\beta\left(t_{B}-t_{A}\right)}$. With probability $\alpha / \beta$, the project starts in class $B$. The board immediately pays the reward, recalls part of the loan, and collects $R I$ and pays $r_{B} D$ for refinancing until the project defaults. Substituting $w^{*}, H^{*}, r_{A}=0$ and $r_{B}=\beta$, we get equation (7).

However, it may not be optimal for the board to implement a contract that induces the manager to monitor and communicate information. Out of equilibrium, the board may profit from low refinancing conditions, but save the reward $H$ or even the efficiency wage $w$. However, lenders anticipate this behavior and 
equilibrium $C$ breaks down. For example, if the monitoring cost $c$ is high in comparison to $\gamma$, then it may be optimal to pay the manager lower incentive wages $w$ (specifically, zero wages). The optimal reward $H$ would then also be zero. If the difference between $R$ and the default intensity in class $\mathrm{B}(\beta)$ is very small, there is little incentive to reduce the bank's outstanding debt. In addition, the board might want to induce the manager to monitor the project, but to not communicate the deterioration of project quality. Examining the board's incentives out of equilibrium, we derive the following conditions (with proof in the appendix). The parameter range is plotted in Figure 2 below on page 18.

Proposition 1 The equilibrium ' $C$ ' with efficiency wage $w>0$ and reward $H>0$ exists if and only if

$$
D \leq \frac{\rho(\alpha+\gamma+\rho)}{\gamma \beta^{2}} c I,
$$

otherwise the board deviates and leaves the reward out of the contract $(H=0)$, and

$$
D \leq \frac{\gamma(\beta-\alpha)}{\alpha(\alpha+\gamma) \beta} R I-\frac{(\alpha+\gamma+\rho)\left(\beta^{2}+\rho(\beta-\alpha)\right)}{\gamma \alpha \beta^{2}} c I,
$$

otherwise the board deviates and sets the wage to zero $(w=0)$.

\subsection{The No-Communication Equilibrium (NC)}

We now discuss equilibrium NC, in which the board induces the manager to monitor the loan, but does not pay a reward when informed about a rating transition. Without the reward, the manager is not incentivized to communicate. We follow the same structure as above in analyzing this equilibrium.

The Lenders. The lenders anticipate remaining uninformed about the project's current class. They must therefore set interest rates according to their beliefs. Initially, the project is in class A with probability $(\beta-\alpha) / \beta$ and class B with probability $\alpha / \beta$. In the first period of duration $\mathrm{d} t$, the expected return is thus

$$
D(1+r \mathrm{~d} t) e^{-\left(\frac{\beta-\alpha}{\beta} \cdot 0+\frac{\alpha}{\beta} \cdot \beta\right) \mathrm{d} t}=D(1+r \mathrm{~d} t)(1-\alpha \mathrm{d} t)=D+D(r-\alpha) \mathrm{d} t .
$$

The participation constraint is binding if $r=\alpha<\beta$ initially. As time elapses, the beliefs about the class of the project might change. We argue that these beliefs are constant in our setting. Let us call $p_{A}(t)$ the probability that the project is in class A at date $t, p_{B}(t)$ the probability that it is in class $\mathrm{B}$, and $p_{D}(t)$ the probability that 
it has already defaulted. Then if the loan is monitored, the following differential equations describe the evolution of probabilities.

$$
\dot{p}_{A}(t)=-\alpha p_{A}(t), \quad \dot{p}_{B}(t)=\alpha p_{A}(t)-\beta p_{B}(t),
$$

with $p_{D}(t)=1-p_{A}(t)-p_{B}(t)$, and $p_{A}(0)=(\beta-\alpha) / \beta, p_{B}(0)=\alpha / \beta, p_{D}(0)=0$. This linear ordinary differential equation has the following solutions:

$$
p_{A}(t)=\frac{\beta-\alpha}{\beta} e^{-\alpha t}, \quad \text { and } \quad p_{B}(t)=\frac{\alpha}{\beta} e^{-\alpha t} .
$$

Both probabilities decrease at the same rate $\alpha$. The probability of a class A project decreases at rate $\alpha$ anyway, and class B projects diminish at rate $\beta$, but new class $B$ projects arrive from class A all the time, so the aggregate growth rate is also $-\alpha$. The reason this arises is that we have chosen an eigenvector of the dynamic system as initial condition, $p_{A}(0)=(\beta-\alpha) / \beta$ and $p_{B}(0)=\alpha / \beta$. This makes the evolution of probabilities especially simple. The probability of being in class $A$, conditional on not being in default, is constant at $(\beta-\alpha) / \alpha$.

The Manager. If the board does not want to induce the manager to communicate, it sets $H=0$. Consequently, we need to calculate the manager's behavior as a function of the wage $w$ only. Assume that the project is currently in class A. The manager's discounted expected utility is then

$$
\begin{aligned}
U_{A} & =\int_{0}^{\infty}\left[\int_{t_{A}}^{\infty}\left(\int_{0}^{t_{A}}(w-c I) e^{-\rho t} \mathrm{~d} t+\int_{t_{A}}^{t_{B}} w e^{-\rho t} \mathrm{~d} t\right) \beta e^{-\beta\left(t_{B}-t_{A}\right)} d t_{B}\right] \alpha e^{-\alpha t_{A}} d t_{A} \\
& =\frac{\alpha+\beta+\rho}{(\alpha+\rho)(\beta+\rho)} w-\frac{c I}{\beta+\rho} .
\end{aligned}
$$

Let us give some intuition. The date $t_{A}$ of transition from $\mathrm{A}$ to $\mathrm{B}$ is distributed with density $f\left(t_{A}\right)=\alpha e^{-\alpha t_{A}}$. For a given $t_{A}$, the final default date $t_{B}$ is distributed with density $\beta e^{-\beta\left(t_{B}-t_{A}\right)}$. Between date 0 and $t_{A}$, the managers receives the wage $w$ net of $c I$, discounted by $e^{-\rho t}$. Between $t_{A}$ and $t_{B}$, she receives the wage but no longer exerts effort. From a project in class $B$, the expected utility would only be

$$
\begin{aligned}
U_{B} & =\int_{0}^{\infty}\left\{\int_{0}^{t_{B}} w e^{-\rho t} \mathrm{~d} t\right\} \beta e^{-\beta t_{B}} d t_{B} \\
& =\frac{w}{\beta+\rho} .
\end{aligned}
$$

Now assume the manager consider deviating from the equilibrium behavior by not monitoring for a short period $\mathrm{d} t$. If she monitors, the expected utility is

$$
\alpha \mathrm{d} t U_{B} e^{-\rho \mathrm{d} t}+(1-\alpha \mathrm{d} t) U_{A} e^{-\rho \mathrm{d} t}+\left(w e^{-\rho \mathrm{d} t}-c I\right) \mathrm{d} t .
$$


If she shirks, the expected utility becomes

$$
(\alpha+\gamma) \mathrm{d} t U_{B} e^{-\rho \mathrm{d} t}+(1-(\alpha+\gamma) \mathrm{d} t) U_{A} e^{-\rho \mathrm{d} t}+w e^{-\rho \mathrm{d} t} \mathrm{~d} t .
$$

In equilibrium, the incentive condition is binding. Setting $(15)=(16)$, taking the limit $\mathrm{d} t \rightarrow 0$ and solving for $w$ yields

$$
w^{*}=\frac{(\alpha+\gamma+\rho)(\beta+\rho)}{\gamma \beta} c I .
$$

The wage is exactly the same as it was in equilibrium C. This is not surprising, given that the manager was just indifferent between taking the reward or not.

The Board. In equilibrium, the bank's expected profit is

$$
\begin{aligned}
\Pi_{\mathrm{NC}}= & \frac{\beta-\alpha}{\beta} \int_{0}^{\infty}\left[\int_{0}^{t_{A}}\left(R I-r D-w^{*}\right) \mathrm{d} t\right. \\
& \left.\quad+\int_{t_{A}}^{\infty}\left(\int_{t_{A}}^{t_{B}}\left(R I-r D-w^{*}\right) \mathrm{d} t\right) \beta e^{-\beta\left(t_{B}-t_{A}\right)} d t_{B}\right] \alpha e^{-\alpha t_{A}} d t_{A} \\
+ & \frac{\alpha}{\beta} \int_{0}^{\infty}\left(\int_{0}^{t_{B}}\left(R I-r D-w^{*}\right) \mathrm{d} t\right) \beta e^{-\beta t_{B}} d t_{B} \\
= & \frac{R I-r D-w^{*}}{\alpha}=\frac{R I}{\alpha}-D-\frac{(\gamma+\alpha+\rho)(\beta+\rho)}{\gamma \alpha \beta} c I, .
\end{aligned}
$$

The earnings $R I$ and the payments $r D$ and $w$ always remain the same as there is no new information revealed until default; however, the probabilities of default differ. With probability $(\beta-\alpha) / \beta$, the project is initially in class $\mathrm{A}$; with probability $\alpha / \beta$ the project is in class $\mathrm{B}$. Date $t_{A}$ denotes the date at which the transition from class A to class B occurs and is characterized by its density, $f\left(t_{A}\right)=\alpha e^{-\alpha t_{A}}$. Date $t_{B}$ denotes the time of default, and is characterized by its density, $f\left(t_{B}\right)=$ $\beta e^{-\beta\left(t_{B}-t_{A}\right)}$. Inserting $w^{*}$ and $r=\alpha$ yields (18). The proof of the following proposition is in the appendix.

Proposition 2 The equilibrium 'NC' with efficiency wage as in (17) but no reward exists if and only if

$$
D \leq \frac{R I}{\alpha}-\frac{(\alpha+\gamma)(\beta+\rho)(\gamma+\alpha+\rho)}{\gamma^{2} \alpha(\beta-\alpha)} c I,
$$

otherwise the board deviates and sets the wage to zero $(w=0)$, and

$$
D \geq \frac{\rho(\gamma+\alpha+\rho)}{\gamma \beta(\beta-\alpha)} c I,
$$

otherwise the board prefers to have a reward for communication $(H>0)$. 
If the monitoring costs $c$ are very high, it may be too expensive for the board to pay the incentive wage $w$. However, if the difference between refinancing costs $\beta$ of class B and the returns of the project is large while the difference between the two transition rates $\beta$ and $\alpha$ is small, the board prefers to receive the information so it may reduce the costly outstanding debt.

\subsection{The Mixed-Strategy Equilibrium}

So far, we have defined two types of equilibrium. However, a mixture of these equilibria can be another type. The boundaries of the two equilibria $C$ and NC are not identical; there is an equilibrium in which both strategies are chosen from randomly that exists in the space between the previous two equilibria.

The higher the debt level and the greater the increase in refinancing costs caused by the warning, the more profitable it is for the board not to pay a reward. However, the increase in refinancing costs caused by the warning is reduced if the board does not pay the reward. Thus, there exists a mixed-strategy equilibrium in which the board randomizes between contracts with and without a reward. In the mixed-strategy equilibrium, we assume the board chooses strategy $\mathrm{C}$ with probability $p_{\mathrm{C}}$ and strategy NC with probability $p_{\mathrm{NC}}=1-p_{\mathrm{C}}$. The lenders anticipate the mixed strategy and require the interest rate $r_{M} i x$ if they have no information about a transition of the project from class A to B, where

$$
\begin{aligned}
r_{\text {Mix }} & =\frac{0 p_{\mathrm{C}} \frac{\beta-\alpha}{\beta}+0\left(1-p_{\mathrm{C}}\right) \frac{\beta-\alpha}{\beta}+\beta\left(1-p_{\mathrm{C}}\right) \frac{\alpha}{\beta}}{p_{\mathrm{C}} \frac{\beta-\alpha}{\beta}+\left(1-p_{\mathrm{C}}\right) \frac{\beta-\alpha}{\beta}+\left(1-p_{\mathrm{C}}\right) \frac{\alpha}{\beta}} \\
& =\frac{\left(1-p_{\mathrm{C}}\right) \alpha \beta}{\beta-\alpha p_{\mathrm{C}}} .
\end{aligned}
$$

The interest rate takes the expected probabilities of default into account. With probability $\frac{\beta-\alpha}{\beta}$, the project is initially in class $\mathrm{A}$, and with probability $\frac{\alpha}{\beta}$ it is in class $\mathrm{B}$. The lenders and the board have exact information about the probability of default only if strategy $\mathrm{C}$ is chosen (with probability $p_{\mathrm{C}}$ ) and the project is in class $\mathrm{B}$; in this case, the probability of default is $\beta$. The other three cases have to be summed and weighted by the sum of their probabilities to calculate $r$. As the respective probabilities of being in class A or B decay at the same rate $\alpha$, the proportions of probabilities remain constant. Therefore, the interest rate $r$ remains constant during this time as well.

The mixed-strategy equilibrium exists if the board is indifferent between playing strategy $\mathrm{C}$ and playing strategy NC. Therefore, we can calculate the probability $p_{\mathrm{C}}$ by setting $\Pi_{\mathrm{NC}}=\Pi_{\mathrm{C}}$ and substituting $w^{*}, H^{*}, r=r_{\mathrm{Mix}}$ and $r_{B}=\beta$,

$$
\frac{R I-r D-w}{\alpha}=\frac{R I}{\alpha}-H-\frac{\alpha r_{B} D+(\beta-\alpha)(w+r D)}{\alpha \beta},
$$




$$
p_{\mathrm{C}}=\frac{\beta}{\alpha}\left(1-\frac{\beta-\alpha}{\rho \frac{\alpha+\gamma+\rho}{\gamma \beta} c} \frac{D}{I}\right) .
$$

In this mixed-strategy equilibrium, the board plays strategy $\mathrm{C}$ with probability $p_{\mathrm{C}}$ and strategy NC with probability $\left(1-p_{\mathrm{C}}\right)$. Substituting the expressions for $r$ and $p_{C}$ given by (21) and (22), the bank's expected return is

$$
\begin{aligned}
\Pi_{\mathrm{Mix}} & =p_{\mathrm{C}} \Pi_{\mathrm{C}}+\left(1-p_{\mathrm{C}}\right) \Pi_{\mathrm{NC}}=\Pi_{\mathrm{C}} \\
& =\frac{1}{\alpha}\left(R I-\beta D-\frac{\alpha+\gamma+\rho}{\gamma} c I\right) .
\end{aligned}
$$

Proposition 3 Outside the parameter ranges for equilibrium $C$ and $N C$, if

$$
D \leq \frac{R I}{\beta}-\left(\alpha+\gamma+\frac{\alpha(\beta+\gamma) \rho}{\beta^{2}}\right) \frac{\alpha+\gamma+\rho}{(\beta-\alpha) \gamma^{2}} c I,
$$

then there is a mixed-strategy equilibrium that is a mixture of strategies $C$ and NC. Strategy $C$ is played with probability $p_{C}$ given by (22) and strategy NC is played with probability $\left(1-p_{C}\right)$.

\subsection{The No-Monitoring Equilibrium}

In the no-monitoring equilibrium (indexed with ' 0 '), the board offers low wages and no reward. Consequently, the manager shirks, the loan is not monitored, and neither the board nor the lenders know whether the project is in class A or B.

The Lenders. Consider equilibrium 0 , in which the board pays neither the reward nor an efficiency wage. Accordingly, the manager does not monitor the project. Starting from a project that is in class A with probability $(\beta-\alpha) / \beta$ and in $\mathrm{B}$ with probability $\alpha / \beta$, the average quality deteriorates continuously over time. Given that the project is not monitored, the transition from class A to B happens relatively quickly compared to a monitored project. This quick transition is anticipated by the lenders. Formally, the decay rate in class A increases to $\alpha+\gamma$. The probabilities $p_{A}(t)$ and $p_{B}(t)$ are no longer an eigenvector of the dynamic system, so the evolution is

$$
\begin{aligned}
& p_{A}(t)=\frac{\beta-\alpha}{\beta} e^{-(\alpha+\gamma) t}, \quad \text { and } \\
& p_{B}(t)=\frac{\beta-\alpha}{\beta} \frac{\alpha+\gamma}{\beta-\alpha-\gamma} e^{-(\alpha+\gamma) t}-\frac{\gamma}{\beta-\alpha-\gamma} e^{-\beta t} .
\end{aligned}
$$


The instantaneous probability of default is given by

$$
\frac{0 \cdot p_{A}(t)+\beta \cdot p_{B}(t)}{p_{A}(t)+p_{B}(t)}=\frac{(\alpha+\gamma)(\beta-\alpha)-\beta \gamma e^{-(\beta-\alpha-\gamma) t}}{\beta-\alpha-\gamma e^{-(\beta-\alpha-\gamma) t}}
$$

In order to break even at each point in time, the interest rate $r(t)$ must be equal to this rate. Finally, the probability that the project has defaulted at date $t_{B}$ is

$$
F\left(t_{B}\right)=1-\left(p_{A}(t)+p_{B}(t)\right)=1-\frac{(\beta-\alpha) e^{-(\alpha+\gamma) t_{B}}-\gamma e^{-\beta t_{B}}}{\beta-(\alpha+\gamma)}
$$

This is the probability distribution function of the default date $t_{B}$. Thus, the density function of the default date $t_{B}$ is

$$
f\left(t_{B}\right)=\frac{(\gamma+\alpha)(\beta-\alpha) e^{-(\alpha+\gamma) t_{B}}-\gamma \beta e^{-\beta t_{B}}}{\beta-(\alpha+\gamma)}
$$

The Board. The bank's expected profit in equilibrium 0 is

$$
\begin{aligned}
\Pi_{0} & =\int_{0}^{\infty} \int_{0}^{t_{B}}(R I-r(t) D) \mathrm{d} t f\left(t_{B}\right) d t_{B} \\
& =\int_{0}^{\infty} \int_{0}^{t_{B}}(R I) \mathrm{d} t f\left(t_{B}\right) d t_{B}-D \\
& =\int_{0}^{\infty}(R I) t_{B} f\left(t_{B}\right) d t_{B}-D=\frac{\gamma+\beta}{(\gamma+\alpha) \beta} R I-D .
\end{aligned}
$$

Until default at date $t_{B}$, the bank earns returns $R I$ and pays interest on its debt $D$; the interest rate is increasing and is given by $r(t)=(26)$. The second equality holds because lenders anticipate the correct default rate; hence, in aggregate, they must be repaid exactly $D$.

Considering out-of-equilibrium behavior by the board, we can now derive conditions under which equilibrium 0 exists. The exact condition and the proof are given in the appendix. The condition differs from those in Propositions 2 and 4, and there can be multiple equilibria. In this case, we concentrate on the Paretodominant equilibrium, which is the communication equilibrium $C$.

Proposition 4 Whenever neither $C$ nor NC nor a mixture between them exists, then either equilibrium 0 (with neither incentive wage nor reward) exists or the bank does not invest at all. 
Figure 2: Equilibria for Different Parameter Constellations

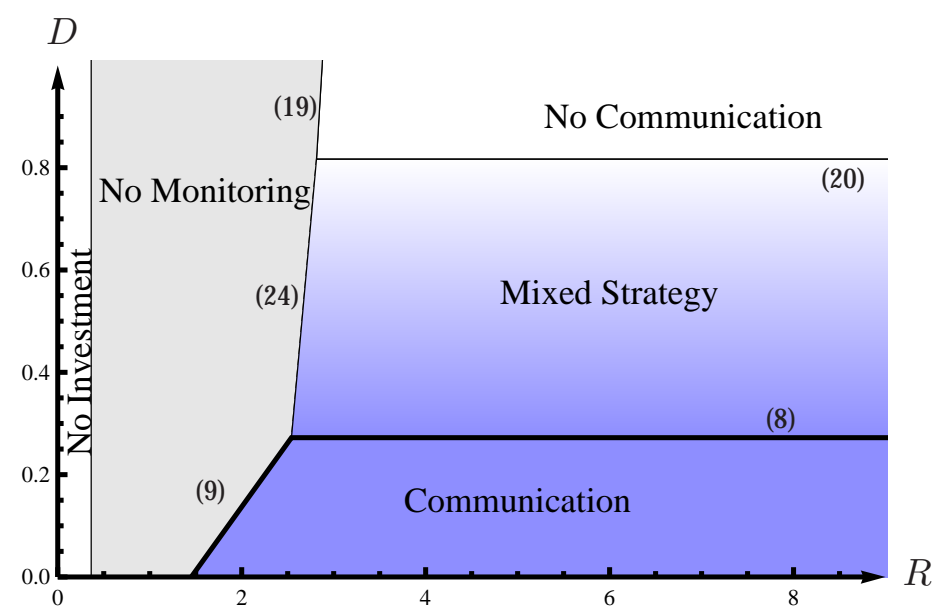

Numbers in brackets indicate the propositions that correspond to the relevant inequalities.

\subsection{Discussion of Factors Influencing Communication}

We have identified three different types of pure-strategy equilibria and one mixedstrategy equilibrium. In the communication equilibrium (C), contracts consist of a reward $H>0$ and an efficiency wage $w>0$. In the no-communication equilibrium $(\mathrm{NC})$, there is no reward, and the information about the deterioration does not become public. In the mixed-strategy equilibrium (Mix), both contracts $\mathrm{C}$ and $\mathrm{NC}$ are implemented with positive probability; therefore, the transmission of information is uncertain. In the no-monitoring equilibrium (0), the manager does not play an active role. The deterioration of project quality progresses quickly. Proposition 4 shows that the parameter space is completely covered with equilibria. Figure 2 depicts the equilibria given parameters $\alpha=1 / 3, \beta=1 / 2, \gamma=1 / 9$, $\rho=9 / 10, c=1 / 160$ and $I=1$ as the debt $D$ and the project return $R$ vary. For very low $R$, there is no investment in the project. For low $R$, there is investment in the project, but the project is not monitored (gray, equilibrium 0 ). In the remaining parameter space, either equilibrium C, Mix or NC is played. The shade of the color in the figure indicates the probability of information transmission. Blue means full communication (C), white means no communication (NC), and light blue means some communication (Mix). The intensity of the blue stands for the probability of a communicative contract.

The conditions in the above propositions show that the general structure of this figure is independent of parameter choices. The equilibrium with communication exists if $D$ is sufficiently low. If $D$ is high, the board fears the information will become public and that financing costs will jump up, which is more costly if $D$ 
is high. Hence, for high $D$, the board does not write a reward into the contract. The same intuition applies for the mixed-strategy equilibrium. As $D$ gets higher, the equilibrium probability that a warning is communicated gets lower. Because $D+E=I, D$ also measures the leverage of the bank; hence, it is negatively related to the equity ratio. We discuss the implications of capital requirements in section 4.2.

The influence of the project return $R$ is also intuitive. For extremely low $R$, the project is not undertaken in the first place. For slightly higher values of $R$, the project is carried out, but it is too expensive for the bank to pay the manager an efficiency wage. $R$ measures the income from the project, hence it can be influenced by different factors. For example, $R$ could be higher during economic upswings or if competition between banks (not explicitly modeled here) is low. In a banking sector with high competition, returns would be lower, which would lead to less informational efficiency. As already mentioned, in difficult times, returns $R$ drop even more; this decrease increases the probability of no communication and exacerbates the problem.

Let us discuss some additional comparative statics that are not immediately visible in the figure. The effect of monitoring costs $c$ on the communication probability is positive: as the manager's monitoring cost $c$ increases, the rent that she collects also increases. Because of the manager's discount rate $\rho$, the bank can economize by offering the manager a one-time payment when the monitoring effort is less important. For that reason, $c$ and $\rho$ enter the expression only as a product. The effect of increasing $\gamma$ is unambiguously negative. Again, this effect arises because of the relationship with the manager's rent. For small $\gamma$, it is difficult to incentivize the manager, so her rent is extremely small. Therefore, paying her off early is a profitable decision for the bank. Finally, both $\alpha$ and $\beta$ influence the communication probability $p_{\mathrm{C}}$ through many channels; hence, it is more difficult to derive an unambiguous intuition for these comparative statics. Ana additional benefit of the information for the bank would move the borders upwards/leftwards. As a result, the region of communication would grow, the mixed-strategy region of would move up.

\section{Policy Implications}

We can now use the model to discuss policy implications. We concentrate on three of many possible applications: capital regulation as the fundamental form of banking regulation, liquidity regulation, and convertible bonds as one new regulatory approach implemented in Basel III. We start with a small welfare analysis, showing that information-efficient contracting enhances welfare. 


\subsection{Welfare Analysis}

Our analysis has no yet determined whether the communication equilibrium is actually the preferred equilibrium for the economy. We define social welfare as the sum of the lenders' profit, the bank's profit $\Pi$ and the manager's utility $U$. Because we assume perfect competition in the market, the lenders make zero profits in any equilibrium. Thus, welfare is only composed of bank's profit and manager's utility because they may receive positive profits and wages. Welfare in the communication equilibrium is

$$
\begin{aligned}
W_{\mathrm{C}} & =\Pi_{\mathrm{C}}+U_{\mathrm{C}} \\
& =\Pi_{\mathrm{C}}+\frac{\beta-\alpha}{\beta} \int_{0}^{\infty}\left[\int_{0}^{t_{A}}(w-c I) e^{-\rho t} \mathrm{~d} t+H e^{-\rho t_{A}}\right] \alpha e^{-\alpha t_{A}} \mathrm{~d} t_{A}+\frac{\alpha}{\beta} H \\
& =\frac{R I}{\alpha}-D-\frac{(\beta-\alpha)(\gamma(\beta+\rho)+\rho(\alpha+\beta+\rho))}{\alpha \gamma \beta^{2}} c I .
\end{aligned}
$$

The manager receives her utility by earning $w$ and incurring cost $c I$ as long as the loan is in class A. After communicating the negative signal, she receives reward $H$. This utility together with the bank's profit results in (30).

Similarly, we calculate welfare in the no-communication equilibrium as

$$
\begin{aligned}
& W_{\mathrm{NC}}=\Pi_{\mathrm{NC}}+U_{\mathrm{NC}} \\
&=\Pi_{\mathrm{NC}}+\frac{\beta-\alpha}{\beta} \int_{0}^{\infty}\left[\int_{0}^{t_{A}}(w-c I) e^{-\rho t} \mathrm{~d} t\right. \\
&\left.+\int_{t_{A}}^{\infty}\left(\int_{t_{A}}^{t_{B}} w e^{-\rho t} \mathrm{~d} t\right) \beta e^{-\beta\left(t_{B}-t_{A}\right)} \mathrm{d} t_{B}\right] \alpha e^{-\alpha t_{A}} \mathrm{~d} t_{A} \\
&+\frac{\alpha}{\beta} \int_{0}^{\infty}\left(\int_{0}^{t_{B}} w e^{-\rho t} \mathrm{~d} t\right) \beta e^{-\beta t_{B}} \mathrm{~d} t_{B} \\
&=\frac{R I}{\alpha}-D-\frac{\rho(\beta+\rho)+\gamma(\beta-\alpha+\rho)}{\alpha \gamma \beta} c I .
\end{aligned}
$$

Accordingly, welfare in the mixed-strategy equilibrium is

$$
\begin{aligned}
W_{\mathrm{Mix}} & =p_{\mathrm{C}}\left(\Pi_{\mathrm{C}}+U_{\mathrm{C}}\right)+\left(1-p_{\mathrm{C}}\right)\left(\Pi_{\mathrm{NC}}+\Pi_{\mathrm{NC}}\right) \\
& =\frac{R I}{\alpha}-\frac{\beta}{\alpha} D-\frac{(\beta-\alpha)(\gamma+\rho)}{\alpha \gamma \beta} c I .
\end{aligned}
$$

By calculating the difference between (30) and (31), one can show that $W_{C}$ is greater than $W_{\mathrm{NC}}$ for all parameters,

$$
W_{\mathrm{C}}-W_{\mathrm{NC}}=\frac{\rho(\alpha+\gamma+\rho)}{\gamma \beta^{2}} c I .
$$


We find that communication is always preferred from a welfare perspective if there are positive wages $w$ that set monitoring incentives for the manager. This is intuitive: the lenders make no profits and the manager is indifferent between the two equilibria because the incentive compatible wage $w^{*}$ is chosen by setting $U_{\mathrm{C}}=U_{\mathrm{NC}}$. Therefore, the difference between $W_{\mathrm{C}}$ and $W_{\mathrm{NC}}$ is simply the difference between the bank's profits in the two equilibria. The bank owners receive a higher profit in the communication equilibrium because they are able to reduce the costly debt. In additional, they pay the smaller one-time payment $H^{*}$ in equilibrium $C$ instead of the larger sum of wages $w^{*}$ from date $t_{A}$ to $t_{B}$ in equilibrium NC; this difference arises because of the manager's discount rate. This leads to the following proposition.

Proposition 5 The welfare in the communication regime is always higher than the welfare in the no-communication regime, that is $W_{C}>W_{N C}$.

Welfare in equilibrium 0 , the no-monitoring equilibrium, is

$$
W_{0}=\Pi_{0}+U_{0}=\frac{\gamma+\beta}{(\alpha+\gamma) \beta} R I-D .
$$

The manager receives neither incentive wage nor reward. Therefore, her utility equals 0 and the total welfare is simply the bank's profit. Whether the welfare in the communication equilibrium is greater than $W_{0}$ depends on the exogenous parameters, as we can see by calculating the difference between (30) and (34),

$$
W_{\mathrm{C}}-W_{0}=\frac{\gamma(\beta-\alpha)}{\alpha \beta(\alpha+\gamma)} R I-\frac{(\beta-\alpha)(\gamma(\beta+\rho)+\rho(\alpha+\beta+\rho))}{\alpha \gamma \beta^{2}} c I .
$$

As the cost of monitoring loans become very high, they reach a level at which it is too expensive to set incentives for monitoring. With costs

$$
c \leq \frac{\gamma^{2} \beta}{(\alpha+\gamma)(\gamma(\beta+\rho)+\rho(\alpha+\beta+\rho))} R,
$$

the equilibrium with communication yields higher welfare than the no-monitoring equilibrium. In summary, it may be possible that no monitoring is better than communication from a welfare perspective depending on the parameters; for example, the ordering varies with the costs $c$. However, with monitoring and low costs $c$, incentives for providing information are always welfare-optimal. 


\subsection{Capital Regulation}

When discussing potential policy measures in the banking sector, capital adequacy standards are a good point of departure. We need to slightly reinterpret the original model to discuss this class of policies. Originally, the initial investment into the project was $I$, of which the debt $D$ was provided by lenders and the remaining $E=I-D$ was the equity stake. Let us now assume that $E$ is fixed and that the maximum investment is given by $E=\kappa I$. Thus, $I=\frac{1}{\kappa} E$. The parameter $\kappa$ marks the (required) equity ratio. We assume that bank owners cannot reinvest profits; therefore, equity does not increase over time. The profits of the bank are distributed to the equity owners; however, equity invested in the current project of the bank remains fixed. We can now discuss the role of an increase in $\kappa$. The question of interest is whether communication can be induced by introducing capital regulation. In addition, we are interested in whether welfare can be enhanced by stricter capital requirements. Therefore, we start our analysis in the mixed strategy region of the parameter space to examine whether the probability of communication increases.

We concentrate on the mixed-strategy equilibrium because a marginal increase in capital regulation can only reduce welfare in any of the other equilibria. This reduction occurs because project size is reduced - leading to a lower welfare--, but the probability of communication (which would increase welfare) is unchanged. In the mixed-strategy equilibrium, the probability of choosing contract $C$ changes from equation (22) to

$$
p_{\mathrm{C}}=\frac{\beta}{\alpha}\left(1-\frac{(\beta-\alpha)(1-\kappa)}{\rho \frac{\alpha+\gamma+\rho}{\gamma \beta} c}\right) .
$$

An increase in $\kappa$ thus leads to a higher value of $p_{C}$. Hence, higher capital regulation leads to a higher probability of communication, a higher informativeness. Welfare in the mixed-strategy equilibrium with capital regulation is

$$
W_{\text {Mix }}=\left(\frac{R}{\alpha \kappa}-\frac{\beta\left(\frac{1}{\kappa}-1\right)}{\alpha}-\frac{(\beta-\alpha)(\gamma+\rho)}{\alpha \gamma \beta \kappa} c\right) E .
$$

The various terms in this expression are readily interpretable. The first term gives the income from the project as long as it is in class A, which depends negatively on $\kappa$. The second term represents refinancing costs. The third term is the cost of incentivizing the manager, which includes the savings from paying her off early. Taking the derivative,

$$
\frac{\partial W_{\text {Mix }}}{\partial \kappa}=\left(\frac{\beta-R}{\alpha \kappa^{2}}+\frac{(\beta-\alpha)(\gamma+\rho)}{\alpha \gamma \beta \kappa^{2}} c\right) E .
$$

Depending on the relative sizes of $\alpha, \beta$ and $R$, this expression could be positive or negative. However, because $\beta>\alpha$, the second summand is positive. 
Proposition 6 The welfare effect of capital requirements is positive if and only if

$$
c>-\frac{\gamma \beta(\beta-R)}{(\beta-\alpha)(\gamma+\rho)} .
$$

Otherwise a higher required equity ratio does not increase the welfare.

Consequently, the derivative is positive if the costs $c$ are high enough; that is, the welfare effect of capital requirements is positive despite the fact that aggregate investment is reduced. The benefit of increased transparency dominates the cost of reduced investment. The preceding analysis establishes that a marginal increase in capital requirements is welfare-positive in the mixed-strategy equilibrium. It is welfare-negative in all other equilibria because it reduces investment volume.

In this setting, it would also be possible to discuss risk-sensitive capital requirements, as introduced in Basel II and retained in Basel III. The asset portfolio of the bank would have to be rated, but this rating could depend only on the available information. Hence, in equilibrium $\mathrm{C}$, the rating would be high (A) before the transition, and lower (B) afterward. In other equilibria, the rating would be somewhere in between because of the lack of available information. Let us assume that the better the rating, the lower the $\kappa$. This would imply that part of the project would have to be sold after a deterioration (deleveraging), possibly at a large discount. ${ }^{6}$ The implications for a bank's incentive to implement an informative contract $(\mathrm{C})$ are largely negative. In reaction to a warning from a manager, markets will realize and react resulting in increased refinancing costs. However, rating agencies will also react by downgrading the bank, which forces it to deleverage at unfavorable prices. In sum, capital regulation is good for the system's informativeness, but requirements must be risk-insensitive.

\subsection{Liquidity Regulation}

In the model, the bank can react to the negative information, but only in one way: it can restructure the manager's wage contract. It cannot sell part of its assets, because we have assumed perfectly illiquid assets. This assumption keeps the model simple, but it is not necessarily realistic. In reality, the bank will want to restructure (or sell) its asset portfolio after the negative information is revealed. As a consequence, the bank has an additional incentive to implement the communication contract. As the information channel is likely unobstructed, the financial

\footnotetext{
${ }^{6}$ These prices are difficult to endogenize in our setting without further assumptions. Thus, we have left this discussion informal.
} 
market becomes more efficient. As a consequence, there is scope for regulation: if the bank does not choose the optimal degree of liquidity itself, the regulator may force it to do so. Of course, the original intention and most important feature of liquidity regulation is the protection of banks against liquidity shocks. However, as can be seen in our model, liquidity regulation also influences communication incentives.

First, we analyze the effect of asset liquidity on information efficiency. To analyze this relationship, we expand our model slightly. Assume that a fraction $\lambda$ of assets can be liquidated at any time at zero cost. The remaining fraction $1-\lambda$ cannot be liquidated. Furthermore, assume that after the project is downgraded, it is optimal to liquidate; that is, assume that $\beta>R$. We discuss conditions under which the communication equilibrium is implemented. The discussion of the other equilibria proceeds along the same lines.

The incentive conditions for the manager are unchanged: $H^{*}$ and $w^{*}$ are still given by (5) and (6), respectively. The expected profits of the bank change because part of the portfolio can be liquidated after the negative information is revealed. For example, (7) becomes

$$
\begin{aligned}
\Pi_{C}= & \frac{\beta-\alpha}{\beta} \int_{0}^{\infty}\left[\int_{0}^{t_{A}}\left(R I-r_{A} D-w^{*}\right) \mathrm{d} t-H^{*}\right. \\
& \left.+\int_{t_{A}}^{\infty}\left(\int_{t_{A}}^{t_{B}}\left(R I(1-\lambda)-r_{B}(D-\lambda I)\right) \mathrm{d} t\right) \beta e^{-\beta\left(t_{B}-t_{A}\right)} d t_{B}\right] \alpha e^{-\alpha t_{A}} \mathrm{~d} t_{A} \\
+ & \frac{\alpha}{\beta}\left[-H^{*}+\int_{0}^{\infty}\left(\int_{0}^{t_{B}}\left(R I(1-\lambda)-r_{B}(D-\lambda I)\right) \mathrm{d} t\right) \beta e^{-\beta t_{B}} d t_{B}\right] \\
= & \frac{R I}{\alpha}+\left(1-\frac{R}{\beta}\right) \lambda I-D-\frac{(\alpha+\gamma+\rho)\left(\beta^{2}+\rho(\beta-\alpha)\right)}{\gamma \alpha \beta^{2}} c I .
\end{aligned}
$$

As for Proposition 1, we now compare these expected profits with the corresponding profits out of equilibrium. We derive conditions for the existence of the communication equilibrium that are very similar to those given by Proposition 1, (8) and (9). The bank will prefer the contract with communication to that without communication only if

$$
D \leq \frac{\rho(\alpha+\gamma+\rho)}{\gamma \beta^{2}} c I+\left(1-\frac{R}{\beta}\right) \lambda I .
$$

It will prefer the contract with communication to that without monitoring only if

$$
D \leq \frac{\gamma(\beta-\alpha)}{\alpha(\alpha+\gamma) \beta}-\frac{(\alpha+\gamma+\rho)\left(\beta^{2}+\rho(\beta-\alpha)\right)}{\gamma \alpha \beta^{2}} c I+\left(1-\frac{R}{\beta}\right) \lambda I .
$$


Both inequalities are weaker than (8) and (9). In each case, the limiting $D$ is larger by $\left(1-\frac{R}{\beta}\right) \lambda I$. As the degree of liquidity $\lambda$ of the assets increases, the communicative contract is more likely to be implemented and the financial market is more information-efficient.

We want to make three more points informally. First, if the bank could choose the degree of liquidity for its assets, what would it choose? Clearly, it would choose $\lambda=1$ if there were no downside to doing so. Assume that the expected return of an asset depends negatively on its liquidity, $R=R(\lambda)$ with $R^{\prime}(\lambda)<$ 0 , such that the problem has an interior solution. Then the bank would choose some degree of liquidity $\lambda^{*}$. If lenders could not observe the asset's liquidity, the bank would choose a $\lambda$ that is too low. In this case, there would be scope for liquidity regulation. Second, in (42) and (43), one can see that as assets become more liquid, the bank can take on more leverage. Therefore, in our context, capital regulation and liquidity regulation are substitutes. Third, we have assumed that a fraction $\lambda$ of assets can be liquidated at no cost. In reality, the saleability of assets will depend on whether the source of distress is idiosyncratic or systemic. In a systemic crisis, many banks will want to sell their assets, and the price will be low. Consequently, liquidity regulation is less beneficial with respect to the communication of crisis warnings.

\subsection{Convertible Bonds}

We have assumed that the bank can finance its loan portfolio solely with debt and inside equity. If we allow for more general financial tools, the equilibria might look different. For example, let us discuss the role of contingent convertible bonds (coco bonds) as an innovative source of finance; this source is considered in Basel III. We show that equilibrium C can be reached when it is welfare-optimal for the following reason: the coco debt is converted into shares at a predefined conversion rate after the value of equity has dropped below some threshold. The original reason for why the board may not want to implement a contract inducing communication is the negative market reaction after a bad signal. In other words, there is a positive externality on investors that is not internalized by the bank. However, by adjusting the conversion rate of the cocos to the right level, this externality can be taken into account.

Without loss of generality, assume there is no straight debt; there are only coco bonds. The volume that needs to be financed by lenders is $D=I-E$ as before. We show that the face value can be different and that debt may have to be issued below par. We denote $\bar{D}$ the face value and $r$ as the short-term interest rate. 
After the negative signal, the project is in class B, hence the aggregate value is

$$
\int_{0}^{\infty} R I t_{B} \beta e^{-\beta t_{B}} \mathrm{~d} t_{B}=\frac{R I}{\beta} .
$$

A fraction $1 /(1+\eta)$ goes to the bank, and the remaining fraction $\eta /(1+\eta)$ goes to lenders. Now remember that the project may be in class B right away, with probability $\alpha / \beta$. The lender then loses part of his investment immediately, and he wants to be compensated for that fact. Therefore,

$$
\begin{aligned}
& D=\frac{\beta-\alpha}{\beta} \bar{D}+\frac{\alpha}{\beta} \cdot \frac{R I}{\beta}, \\
& \bar{D}=\frac{\beta}{\beta-\alpha} D-\frac{\eta}{1+\eta} \frac{\alpha}{\beta-\alpha} \frac{R I}{\beta} .
\end{aligned}
$$

After this initial period, the interest rate $r$ adjusts such that lenders break even:

$$
\begin{aligned}
\bar{D} & =\alpha \mathrm{d} t \frac{\eta}{1+\eta} \cdot \frac{R I}{\beta}+(1-\alpha \mathrm{d} t)(1+r \mathrm{~d} t) \bar{D}, \\
r & =\alpha\left(1-\frac{\eta}{1+\eta} \frac{R I}{\beta n}\right) .
\end{aligned}
$$

The second line obtains by solving for $r$ and taking the limit $\mathrm{d} t \rightarrow 0$. We can now calculate the bank's expected profit within equilibrium C, i. e., the equilibrium with a reward and the efficiency wage. This quantity consists of two parts: the expected profits before the negative signal and the profits after the signal.

$$
\begin{aligned}
\Pi_{\mathrm{C}} & =\frac{\beta-\alpha}{\beta} \int_{0}^{\infty}(R I-w-r \bar{D}) t_{A} \alpha e^{-\alpha t_{A}} \mathrm{~d} t_{A}-H+\frac{1}{1+\eta} \frac{R I}{\beta} \\
& =\frac{R I}{\alpha}-D-\frac{(\alpha+\gamma+\rho)\left(\beta^{2}+\rho(\beta-\alpha)\right)}{\gamma \alpha \beta^{2}} c .
\end{aligned}
$$

The second line obtains by inserting the optimal $w^{*}$ and $H^{*}$ from (5) and (6), respectively, and the equilibrium $\bar{D}$ from (45). Note that this equilibrium profit is identical to that in the informative equilibrium with debt financing only, as given by (7). This is not surprising because the expected profits of lenders are always zero and those of the manager are unchanged. In addition, $\eta$ drops out of the equation. A higher $\eta$ is exactly compensated by lower interest rates $r$. We now need to check the conditions under which the board wants to drop the reward. Out of equilibrium, the board's expected profit is

$$
\begin{aligned}
\Pi_{C}^{\prime} & =\frac{\beta-\alpha}{\beta} \int_{0}^{\infty}(R I-w-r \bar{D}) t_{A} \alpha e^{-\alpha t_{A}} \mathrm{~d} t_{A}+\int_{0}^{\infty}(R I-w-r \bar{D}) t_{B} \alpha e^{-\alpha t_{B}} \mathrm{~d} t_{B} \\
& =\frac{1}{\beta-\alpha}\left(\left(\frac{\beta}{\alpha}-\frac{1}{1+\eta}\right) R I-\beta D\right)-\frac{(\beta+\rho)(\alpha+\gamma+\rho)}{\gamma \beta} c
\end{aligned}
$$


For a given $\eta$, the board chooses to implement the reward if $\Pi_{C} \geq \Pi_{C}^{\prime}$; that is, the reward is implemented if

$$
D \leq \frac{\eta}{1+\eta} \frac{R I}{\alpha}-\frac{\beta-\alpha}{\beta} \frac{\rho(\alpha+\gamma+\rho)}{\alpha \beta \gamma} c .
$$

In section 4.1, we showed that the equilibrium with a reward always dominates the equilibrium with monitoring only. Hence, in order to achieve the communication equilibrium $C$, one needs to set $\eta$ high enough such that (49) is binding. Taking the limit as $\eta \rightarrow \infty$, the reward is implemented if $D \leq R / \alpha$. But $R / \alpha$ is the expected return from the project; a project with $D>R / \alpha$ would not be financed in the first place. As a result, the communication equilibrium can always be obtained. The following proposition sums up these arguments.

Proposition 7 Starting from the no-communication equilibrium (NC), financing with appropriate contingent convertible bonds induces the board to implement contracts with a reward such that the communication equilibrium obtains.

Also in the no-monitoring equilibrium, one can show that finance through coco bonds can lead to the communication equilibrium. For a given $\eta$, the profit without efficiency wage is

$$
\Pi_{\mathrm{C}}^{\prime \prime}=\frac{\beta+\gamma}{\beta-\alpha}\left(\frac{\beta(1+\eta)-\alpha}{\beta(1+\eta)(\alpha+\gamma)} R-\frac{\alpha}{\alpha+\gamma} D\right) .
$$

The board chooses to implement efficiency wages and reward if $\Pi_{C}>\Pi_{C}^{\prime \prime}$ :

$$
\begin{gathered}
D \leq \frac{(\beta-\alpha)(\alpha+\gamma)}{\alpha^{2}+\gamma(2 \alpha-\beta)}\left(\left(\frac{(\beta+\gamma)(\beta(1+\eta)-\alpha}{(\beta-\alpha) \beta(\alpha+\gamma)(1+\eta)}-\frac{1}{\alpha}\right) R\right. \\
\left.\quad+\frac{(\alpha+\gamma+\rho)\left(\beta^{2}+(\beta-\alpha) \rho\right)}{\alpha \beta^{2} \gamma} c\right) .
\end{gathered}
$$

The derivative of this term with respect to $\eta$ is positive. This means that as $\eta$ increases, the bank can take on more debt without destroying the communication channel.

\section{Conclusion}

We have constructed a microeconomic model of a bank in which communication of negative information, potentially about an upcoming crisis, plays a crucial role. 
The board would like to react to bad news by eliminating the manager's monitoring duties. However, the board needs to persuade the manager to report the news in the first place. The refinancing markets take notice of the board's reaction to the bad news; hence, the news is incorporated into market prices. This means higher refinancing costs for the bank. From a welfare perspective, the board has insufficient incentives to implement an informative contract; that is, financial markets are always semi-strong form efficient, and they become strongform efficient when the informative contract is chosen. The degree of information efficiency is endogenous.

The model matches a number of stylized facts from the recent financial crisis. First and foremost, it explains how it is possible that crucial information could remain hidden for such a long time. Because many financial institutions were highly leveraged, the effect on refinancing costs would have been disastrous. So even if individuals within financial institutions could have foreseen the crisis, the institutions would not have wanted to incentivize them to report this information. Referring back to Figure 2, this situation is specific to highly leveraged institutions. Furthermore, many assets of financial institutions (e. g., mortgage loans) seemed to be highly liquid before the crisis, but proved to be illiquid during the crisis. It was impossible to cancel or reverse housing loans, because borrowers would have simply defaulted. In our model, a low level of asset liquidity results in a low level of informativeness.

We have modeled the bank as a single institution, and so there are no systemic effects. Modeling a banking system would have many consequences that would push outcomes in different directions. For example, the information about the deterioration of the loan portfolio may trigger further allocative decisions. In the communication equilibrium, the capital market is strongly information-efficient. In the other equilibria, it is not. This implies that financial markets serve their informational function less effectively in the uninformative equilibria.

As another example, if the loan portfolios of several banks are stochastically dependent, a manager's contract will contain information about other banks. If one bank gets into trouble, the probability that another bank's project deteriorates increases. Consequently, the optimal reward decreases. This might induce some form of competition between managers to be the first to report the deterioration.

Even abstracting from systemic effects, we can discuss a number of important implications. A higher equity ratio means that the bank fears the deterioration of credit conditions less; hence, it is incentivized to implement a communicative contract that results in early warnings to the markets. Capital requirements force banks to deleverage and thus reduce aggregate investment. But the benefits of increased transparency, including the responses taken by the banks themselves, dominate the costs of reduced investment. In other words, it is better to invest 
less if this enables banks to optimally react to negative news that would otherwise have been suppressed. Introducing a risk-sensitive capital requirement is detrimental. A possible liquidation of assets has a positive effect on the probability of implementation of the communicative contract; hence, liquidity regulation can be beneficial to the economy. Contingent convertible bonds can also increase welfare if the conversion rate is fixed low enough such that it reduces pressure from refinancing markets. In all applications, we stress that policies should be designed such that the communication channel is not obstructed.

\section{A Proofs}

Proof of Lemma 1. To calculate the optimal wage $w_{A} *$ and the optimal reward $H^{*}$, we set the manager's expected utility when monitoring equal to her expected utility when she is not monitoring, that is $(3)=(4)$. In the next step, we use our result that the reward $H$ must equal the expected utility $U_{B}$ as in (1). The condition is binding because the board will pay only the minimum amount required to incentivize the manager to communicate. In this case, the manager is just indifferent between telling bad news to the board and not communicating. By solving these conditions for $w_{A}^{*}$ and $H^{*}$ and taking the limit $\mathrm{d} t \rightarrow 0$, we receive (5) and (6).

Proof of Proposition 1. When does the board prefer to (out of equilibrium) implement contracts with lower wages or a lower reward? We calculate the board's expected profits for these strategies. If, out of equilibrium, the board would write the manager a contract without reward, then the board would have to pay the manager until the project defaults. However, refinancing costs would never adjust from $r_{A}$ to $r_{B}$. Consequently, the aggregate payoff to the bank would be

$$
\begin{aligned}
\Pi_{C}^{\prime}= & \frac{\beta-\alpha}{\beta} \int_{0}^{\infty}\left[\int_{0}^{t_{A}}\left(R I-r_{A} D-w\right) \mathrm{d} t\right. \\
& \left.+\int_{t_{A}}^{\infty}\left(\int_{t_{A}}^{t_{B}}\left(R I-r_{A} D-w\right) \mathrm{d} t\right) \beta e^{-\beta\left(t_{B}-t_{A}\right)} d t_{B}\right] \alpha e^{-\alpha t_{A}} d t_{A} \\
+ & \frac{\alpha}{\beta}\left[\int_{0}^{\infty}\left(\int_{0}^{t_{B}}\left(R I-r_{A} D-w\right) \mathrm{d} t\right) \beta e^{-\beta t_{B}} d t_{B}\right] \\
= & \frac{R I-w^{*}-r_{A} D}{\alpha} \\
= & \frac{R I}{\alpha}-\frac{(\beta+\rho)(\gamma+\alpha+\rho)}{\gamma \beta \alpha} c I .
\end{aligned}
$$

The last line is obtained by substituting $w^{*}$ and setting $r_{A}=0$. 
The board chooses a reward and a positive wage only if $\Pi_{C}^{\prime} \leq \Pi_{C}$; that is, if

$$
\begin{aligned}
\frac{R I}{\alpha}-\frac{(\beta+\rho)(\gamma+\alpha+\rho)}{\gamma \beta \alpha} c I & \leq \frac{R I}{\alpha}-D-\frac{(\alpha+\gamma+\rho)\left(\beta^{2}+\rho(\beta-\alpha)\right)}{\gamma \alpha \beta^{2}} c I \\
D & \leq \frac{\rho(\alpha+\gamma+\rho)}{\gamma \beta^{2}} c I .
\end{aligned}
$$

If, again out of equilibrium, the board would set up a contract with neither reward nor efficiency wage, the aggregate payoff to the board would be

$$
\begin{aligned}
\Pi_{C}^{\prime \prime}= & \frac{\beta-\alpha}{\beta} \int_{0}^{\infty}\left[\int_{0}^{t_{A}}\left(R I-r_{A} D\right) \mathrm{d} t\right. \\
& \left.+\int_{t_{A}}^{\infty}\left(\int_{t_{A}}^{t_{B}}\left(R I-r_{A} D\right) \mathrm{d} t\right) \beta e^{-\beta\left(t_{B}-t_{A}\right)} d t_{B}\right](\alpha+\gamma) e^{-(\alpha+\gamma) t_{A}} d t_{A} \\
+ & \frac{\alpha}{\beta}\left[\int_{0}^{\infty}\left(\int_{0}^{t_{B}}\left(R I-r_{A} D\right) \mathrm{d} t\right) \beta e^{-\beta t_{B}} d t_{B}\right] \\
= & \frac{\left(R I-r_{A} D\right)(\gamma+\beta)}{\beta(\alpha+\gamma)}=\frac{(\gamma+\beta)}{\beta(\alpha+\gamma)} R I .
\end{aligned}
$$

The manager chooses a reward plus a positive wage only if $\Pi_{\mathrm{C}}^{\prime \prime} \leq \Pi_{\mathrm{C}}$ :

$$
\begin{gathered}
\frac{(\gamma+\beta)}{\beta(\alpha+\gamma)} R I \leq \frac{R I}{\alpha}-D-\frac{(\alpha+\gamma+\rho)\left(\beta^{2}+\rho(\beta-\alpha)\right)}{\gamma \alpha \beta^{2}} c I \\
D \leq \frac{\gamma(\beta-\alpha)}{\alpha(\alpha+\gamma) \beta} R I-\frac{(\alpha+\gamma+\rho)\left(\beta^{2}+\rho(\beta-\alpha)\right)}{\gamma \alpha \beta^{2}} c I .
\end{gathered}
$$

We have to prove one more proposition. Up to now, we have implicitly assumed that the board implements the contract once and for all. However, given that all contracts are only short-term, the board may change the contract at any time. For example, it may start with a low wage, but increase the wage after some time. However, one can show that the reward does not depend on the probability with which the board expects the project to be in class A or B because both the reward and reduced wage costs apply only under the condition that a transition occurs; hence, the probability cancels out. Furthermore, because the board is always informed about the project's class, the efficiency wage does not change over time. Therefore, when (53) and (55) hold, the board writes a contract with an efficiency wage and a positive reward.

Proof of Proposition 2. The board can deviate from the equilibrium in two ways. First, it can pay zero wages and the manager shirks. The expected return to the board is then

$$
\Pi_{\mathrm{NC}}^{\prime}=\frac{\beta-\alpha}{\beta} \int_{0}^{\infty}\left[\int_{0}^{t_{A}}(R I-r D) \mathrm{d} t\right.
$$




$$
\begin{aligned}
& \left.+\int_{t_{A}}^{\infty}\left(\int_{t_{A}}^{t_{B}}(R I-r D) \mathrm{d} t\right) \beta e^{-\beta\left(t_{B}-t_{A}\right)} d t_{B}\right](\alpha+\gamma) e^{-(\alpha+\gamma) t_{A}} d t_{A} \\
+ & \frac{\alpha}{\beta} \int_{0}^{\infty}\left(\int_{0}^{t_{B}}(R I-r D) \mathrm{d} t\right) \beta e^{-\beta t_{B}} d t_{B} \\
= & \frac{(R I-\alpha D)(\gamma+\beta)}{\beta(\gamma+\alpha)} .
\end{aligned}
$$

Comparing this expression with (18), the board implements the efficiency wage if $\Pi_{\mathrm{NC}}>\Pi_{\mathrm{NC}}^{\prime}$ :

$$
D \leq \frac{R I}{\alpha}-\frac{(\alpha+\gamma)(\beta+\rho)(\gamma+\alpha+\rho)}{\gamma^{2} \alpha(\beta-\alpha)} c I .
$$

Second, the board can deviate by paying the wage and the reward. The manager then monitors and communicates all news. In this case, the bank's expected profit is

$$
\Pi_{\mathrm{NC}}^{\prime \prime}=\frac{R I}{\alpha}-\frac{2 \beta-\alpha}{\beta} D-\frac{(\gamma+\alpha+\rho)\left(\beta^{2}+\rho(\beta-\alpha)\right)}{\gamma \alpha \beta^{2}} c I .
$$

The board pays efficiency wages but no reward only if $\Pi_{\mathrm{NC}}>\Pi_{\mathrm{NC}}^{\prime \prime}$ :

$$
D \geq \frac{\rho(\gamma+\alpha+\rho)}{\gamma \beta(\beta-\alpha)} c I
$$

Hence, when (57) and (59) hold, there is an equilibrium with a positive wage, $w>0$, and a zero reward, $H=0$.

Proof of Proposition 3. The boundaries of the mixed-strategy equilibrium are defined by the conditions under which the board would deviate from it. Instead of playing a mixed strategy, the board could decide to implement a contract with incentive wage and reward for certain. The expected return to the board is then

$$
\begin{aligned}
\Pi_{\text {Mix }}^{\prime} & =\frac{R I}{\alpha}-H^{*}-\frac{\alpha r_{B} D+(\beta-\alpha)\left(w^{*}+r D\right)}{\alpha \beta} \\
& =\frac{R I}{\alpha}-D-\frac{(\alpha+\gamma+\rho)\left(\beta^{2}+\rho(\beta-\alpha)\right)}{\gamma \alpha \beta^{2}} c I .
\end{aligned}
$$

The second line is obtained by inserting $w^{*}, H^{*}$ and setting $r=r_{\text {Mix }}, r_{B}=\beta$. Because strategy $C$ is definitely chosen, $p_{C}=1$. The board plays the mixed strategy only if $\Pi_{\mathrm{Mix}}>\Pi_{\mathrm{Mix}}^{\prime}$ :

$$
D \geq \frac{\rho(\alpha+\gamma+\rho)}{\gamma \beta^{2}} c I
$$


The board could instead decide to play strategy NC for certain and pay only an incentive wage but no reward to the manager. In that case, its profit would be

$$
\begin{aligned}
\Pi_{\text {Mix }}^{\prime \prime} & =\frac{R I-r D-w}{\alpha} \\
& =\frac{R I}{\alpha}-D-\frac{(\gamma+\alpha+\rho)(\beta+\rho)}{\gamma \alpha \beta} c I .
\end{aligned}
$$

Again, the second line is obtained by inserting $w^{*}$ and setting $r=r_{\text {Mix }}$. In this case, strategy NC is definitely chosen so that $p_{\mathrm{C}}=0$. The board plays the mixed strategy only if $\Pi_{\text {Mix }}>\Pi_{\text {Mix }}^{\prime \prime}$ :

$$
D \leq \frac{\rho(\alpha+\gamma+\rho)}{\gamma \beta(\beta-\alpha)} c I .
$$

Conditions (61) and (63) are identical to equations (8) and (20) from Propositions 1 and 2, respectively. Thus, the mixed-strategy equilibrium is located exactly between equilibrium $\mathrm{C}$ and equilibrium $\mathrm{NC}$.

There is one more possible deviation from the mixed-strategy equilibrium. If the board decides to pay neither an incentive wage nor a reward, then its profit would be

$$
\begin{aligned}
\Pi_{\text {Mix }}^{\prime \prime \prime} & =\int_{0}^{\infty} \int_{0}^{t_{B}}(R I-r D) \mathrm{d} t f\left(t_{B}\right) d t_{B} \\
& =\frac{\beta+\gamma}{\alpha+\gamma}\left(\frac{R I}{\beta}-D+\frac{\rho(\alpha+\gamma+\rho)}{\beta^{2} \gamma} c I\right) .
\end{aligned}
$$

Inserting $p_{\mathrm{C}}$ and setting $r=r_{\text {Mix }}$ leads to the second line. The board prefers the mixed strategy to a contract without incentive wage and reward if $\Pi_{\text {Mix }}>\Pi_{\text {Mix }}^{\prime \prime \prime}$ :

$$
D \leq \frac{R I}{\beta}-\left(\alpha+\gamma+\frac{\alpha(\beta+\gamma) \rho}{\beta^{2}}\right) \frac{\alpha+\gamma+\rho}{(\beta-\alpha) \gamma^{2}} c I .
$$

If equations (61), (63) and (65) hold, an mixed-strategy equilibrium with positive probabilities on strategies $\mathrm{C}$ and NC exists.

Proof of Proposition 4. We need to establish for which parameters out of equilibrium behavior may be optimal for the board. For example, the board may want to pay the manager an efficiency wage, in which case the deterioration of the project is not as fast. We must calculate the expected profits in this case. The density function of the default date $t_{B}$ is simply

$$
\hat{f}\left(t_{B}\right)=\alpha e^{-\alpha t_{B}} .
$$


The bank's expected profit consists of three parts: the expected returns from the project, the expected wages, and the expected refinancing costs. The first two parts are simply

$$
\int_{0}^{\infty}(R I-w) t_{B} \hat{f}\left(t_{B}\right) d t_{B}=\frac{R I-w}{\alpha} .
$$

The third part is

$$
\begin{aligned}
& \int_{0}^{\infty}\left[\int_{0}^{t_{B}} r(t) D \mathrm{~d} t\right] \hat{f}\left(t_{B}\right) d t_{B} \\
& =D \cdot \int_{0}^{\infty}\left[\int_{0}^{t_{B}} \frac{(\alpha+\gamma)(\beta-\alpha)-\beta \gamma e^{-(\beta-\alpha-\gamma) t}}{(\beta-\alpha)-\gamma e^{-(\beta-\alpha-\gamma) t}} \mathrm{~d} t\right] \alpha e^{-\alpha t_{B}} d t_{B} \\
& =D \cdot \int_{0}^{\infty}\left[(\alpha+\gamma) t_{B}-\log \left(\frac{\beta-\alpha-\gamma e^{-(\beta-\alpha-\gamma) t_{B}}}{\beta-\alpha-\gamma}\right)\right] \alpha e^{-\alpha t_{B}} d t_{B} \\
& =D \cdot \int_{0}^{\infty}\left[(\alpha+\gamma) t_{B}+\log (\beta-\alpha-\gamma)-\log \left(\beta-\alpha-\gamma e^{-(\beta-\alpha-\gamma) t_{B}}\right)\right] \alpha e^{-\alpha t_{B}} d t_{B} \\
& =D \cdot\left[\frac{\alpha+\gamma}{\alpha}+\log (\beta-\alpha-\gamma)-\int_{0}^{\infty} \log \left(\beta-\alpha-\gamma e^{-(\beta-\alpha-\gamma) t_{B}}\right) \alpha e^{-\alpha t_{B}} d t_{B}\right] \\
& =D \cdot\left[\frac{\alpha+\gamma}{\alpha}-\frac{\gamma}{\beta-\alpha} \cdot \Phi\left(\frac{\gamma}{\beta-\alpha}, 1, \frac{\beta-\gamma}{\beta-\alpha-\gamma}\right)\right]
\end{aligned}
$$

where the Lerch transcendent $\Phi$ is defined by $\Phi(z, 1, a)=\sum_{n=0}^{\infty} z^{n} /(a+n)$. The aggregate expected profit consists of (67) net of (68):

$$
\Pi_{0}^{\prime}=\frac{R I-w^{*}}{\alpha}-D \cdot\left[\frac{\alpha+\gamma}{\alpha}-\frac{\gamma}{\beta-\alpha} \cdot \Phi\left(\frac{\gamma}{\beta-\alpha}, 1, \frac{\beta-\gamma}{\beta-\alpha-\gamma}\right)\right]
$$

with $w^{*}$ as defined in (5). The board implements the naked contract (without efficiency wage or reward) only if $\Pi_{0} \geq \Pi_{0}^{\prime}$ :

$$
D \geq \frac{\beta-\alpha}{\gamma^{2}(\gamma+\alpha) \beta} \cdot \frac{\gamma^{2}(\beta-\alpha) R I-(\gamma+\alpha)(\beta+\rho)(\gamma+\alpha+\rho) c I}{\beta-\alpha\left[1+\Phi\left(\frac{\gamma}{\beta-\alpha}, 1, \frac{\beta-\gamma}{\beta-\alpha-\gamma}\right)\right]} .
$$

Finally, we must calculate potential out of equilibrium profits if the board wants to implement a contract with both an efficiency wage and a reward. As long as the manager does not reveal the information, lenders believe they are financing a project of mixed quality; hence, they demand the loan rate $r(t)$ as defined in (26). Once the negative signal is communicated, lenders learn they have had wrong beliefs; they then charge the rate $r=\beta$, which is consistent with the correct instantaneous probability of default. The profit function can be expressed as several parts. First, with probability $(\beta-\alpha) / \beta$, the project starts in class $\mathrm{A}$ and the interest 
rate is $r(t)$. The date of the transition to class B is exponentially distributed with parameter $\alpha$. The profit is

$$
\begin{aligned}
& \int_{0}^{\infty}\left[\int_{0}^{t_{A}}(R I-w-r(t) D) \mathrm{d} t\right] \alpha e^{-\alpha t_{A}} d t_{A} \\
& =\frac{R I-w^{*}}{\alpha}-D \cdot\left[\frac{\alpha+\gamma}{\alpha}-\frac{\gamma}{\beta-\alpha} \cdot \Phi\left(\frac{\gamma}{\beta-\alpha}, 1, \frac{\beta-\alpha}{\beta-\alpha-\gamma}\right)\right],
\end{aligned}
$$

which is analogous to (68). Then at date $t_{A}$, the reward $H$ is paid, and the project continues with reduced investment size until it defaults completely. This happens with instantaneous probability $\beta$; hence, the interest rate is also $\beta$.

$$
\begin{aligned}
& \int_{0}^{\infty}\left[\int_{0}^{t_{B}}\left(R I-r_{B} D\right) \mathrm{d} t\right] \alpha e^{-\alpha t_{B}} d t_{B} \\
& =\frac{R I}{\beta}-D .
\end{aligned}
$$

With probability $\alpha / \beta$, the loan starts in class B right away, and the profit is as given by (72). The aggregate expected profit is then $1 \cdot(72)+(\beta-\alpha) / \beta \cdot(71)$, which is

$$
\begin{aligned}
\Pi_{0}^{\prime \prime}= & \frac{R I}{\beta}-D \\
& \quad+\frac{\beta-\alpha}{\beta} \cdot\left[\frac{R I-w^{*}}{\alpha}-D \cdot\left[\frac{\alpha+\gamma}{\alpha}-\frac{\gamma}{\beta-\alpha} \cdot \Phi\left(\frac{\gamma}{\beta-\alpha}, 1, \frac{\beta-\alpha}{\beta-\alpha-\gamma}\right)\right]\right] \\
= & \frac{\beta}{\alpha \beta} R I-\left(1+\frac{(\beta-\alpha)(\alpha+\gamma)}{\alpha \beta}\right) D \\
& \quad+\frac{(\alpha \beta-(\beta-\alpha)(\beta+\rho))(\alpha+\gamma+\rho)}{\gamma \alpha \beta^{2}} c I+\frac{\gamma}{\beta} D \Phi\left(\frac{\gamma}{\beta-\alpha}, 1, \frac{\beta-\gamma}{\beta-\alpha-\gamma}\right) .
\end{aligned}
$$

Hence, the board implements the naked contract only if $\Pi_{0} \geq \Pi_{0}^{\prime \prime}$ :

$$
\frac{D}{I} \geq \frac{(\beta-\alpha) \gamma^{2} \beta R-(\alpha+\gamma)((\beta-\alpha)(\beta+\rho)-\alpha \beta)(\alpha+\gamma+\rho) c}{\gamma(\alpha+\gamma) \beta\left[(\beta-\alpha)(\alpha+\gamma)-\alpha \gamma \Phi\left(\frac{\gamma}{\beta-\alpha}, 1, \frac{\beta-\alpha}{\beta-\alpha-\gamma}\right)\right]}
$$

The board only conducts the project if the bank's profit suffices to pay back at least the invested equity. Therefore, the returns of the project must be high enough:

$$
\Pi_{0} \geq I-D \quad \Longrightarrow \quad R \geq \frac{\beta(\alpha+\gamma)}{\beta+\gamma}
$$




\section{References}

Aghion, P., P. Bolton, And J. Tirole (2004): “Exit Options in Corporate Finance: Liquidity vs. Incentives," Review of Finance, 8(3), 327-353.

Aghion, P., And J. Tirole (1997): "Formal and Real Authority in Organizations," Journal of Political Economy, 105(1), 1-29.

BARRO, J. R., AND R. J. BARRO (1990): “Pay, Performance, and Turnover of Bank CEOs," Journal of Labor Economics, 8(4), 448-481.

Benmelech, E., E. Kandel, And P. Veronesi (2010): “Stock-Based Compensation and CEO (Dis)Incentives," Quarterly Journal of Economics, 125(4), 17691820.

Biais, B., T. Mariotti, G. Plantin, and J.-C. Rochet (2007): “Dynamic Security Design: Convergence to Continuous Time and Asset Pricing Implications," Review of Economic Studies, 47(4), 345-390.

Biais, B., T. MARiotti, J.-C. Rochet, And S. Villeneuve (2010): “Large Risks, Limited Liability, and Dynamic Moral Hazard," Econometrica, 78(1), 73-118.

CARrillo, J. D., And T. MARIOTTI (2000): "Strategic Ignorance as a SelfDisciplining Device," The Review of Economic Studies, 67(3), 529-544.

DeMarzo, P., And Y. SAnNikov (2006): “Optimal Security Design and Dynamic Capital Structure in a Continuous-Time Agency Model," Journal of Finance, 61(6), 2681-2724.

DeMarzo, P. M., And M. J. Fishman (2007): “Agency and Optimal Investment Dynamics," The Review of Financial Studies, 20(1), 151-188.

DyCK, A., A. Morse, And L. Zingales (2010): "Who Blows the Whistle on Corporate Fraud?," The Journal of Finance, 65(6), 2213-2253.

EIsfeldT, A. L., AND A. A. RAMPINI (2008): “Managerial Incentives, Capital Reallocation, and the Business Cycle," Journal of Financial Economics, 87, 177199.

FAhlenbrach, R., And R. M. Stulz (2011): “Bank CEO Incentives and the Credit Crisis," Journal of Financial Economics, 99, 11-26.

JOHn, K., H. MeHRAN, And Y. QIAN (2010): "Outside Monitoring and CEO Compensation in the Banking Industry," Journal of Corporate Finance, 16(4), 483399. 
KANODiA, C., R. BUSHMAN, AND J. DicKHAUt (1989): “Escalation Errors and the Sunk Cost Effect: An Explanation Based on Reputation and Information Asymmetries," Journal of Accounting Research, 27(1), 59-77.

KASRIEL, P. L. (2004): “Collateral Damage from a U.S. Housing Bust," Positive Economic Commentary, The Northern Trust Company, July, 30.

KeSSLER, A. S. (1998): "The Value of Ignorance," The Rand Journal of Economics, 29(2), 339-354.

LAUX, C., G. LóRÁNTH, AND A. MORRISON (2009): “Internal Reporting Systems, Compensation Contracts, and Bank Regulation," CEPR Discussion Paper 7179.

LevitT, S. D., AND C. M. SNyder (1997): “Is no News Bad News? Information Transmission and the Role of "Early Warning" in the Principal-Agent Model," The RAND Journal of Economics, 28(4), 641-661.

PAGÈS, H. (2013): "Bank Monitoring Incentives and Optimal ABS," Journal of Financial Intermediation, 22(1), 30-54.

PAGÈs, H., AND D. PossAMAI (2012): “A Mathematical Treatment of Bank Monitoring Incentive," Banque de France Document de Travail No. 378.

Povel, P. (1999): "Optimal 'Soft' or 'Tough' Bankcruptcy Procedures," Journal of Law, Economics, and Organization, 15(3), 659-684.

Povel, P., R. Singh, And A. Winton (2007): "Booms, Busts, and Fraud," Review of Financial Studies, 20(4), 1219-1254.

QUADRINI, V. (2004): “Investment and Liquidation in Renegotiation-proof Contracts with Moral Hazard," Journal of Monetary Economics, 51(4), 713-751.

RajAN, R. G. (2006): “Has Finance Made the World Riskier?," European Financial Management, 12(4), 499-533.

SANNIKOV, Y. (2007): "Games with Imperfectly Observable Actions in Continuous Time," Econometrica, 75(5), 1285-1329.

- (2008): "A Continuous-Time Version of the Principal-Agent Problem," Review of Economic Studies, 75(3), 957-984.

SHILler, R. J. (2005): Irrational Exuberance. University Presses of Ca, 2 edn.

TiRole, J. (2006): The Theory of Corporate Finance. Princeton University Press.

VerReCchiA, R. E. (2001): "Essays on Disclosure," Journal of Accounting and Economics, 32(1-3), 97-180. 